\title{
Pathway-Specific Drive of Cerebellar Golgi Cells Reveals Integrative Rules of Cortical Inhibition
}

\author{
(DSawako Tabuchi, ${ }^{1}$ Jesse I. Gilmer, ${ }^{1,2}$ Karen Purba, ${ }^{1}$ and ${ }^{\circledR}$ Abigail L. Person ${ }^{1}$ \\ ${ }^{1}$ Department of Physiology \& Biophysics, and ${ }^{2}$ Neuroscience Graduate Program, University of Colorado Denver, University of Colorado School of Medicine, \\ Aurora, Colorado 80045
}

Cerebellar granule cells ( $\mathrm{GrCs}$ ) constitute over half of all neurons in the vertebrate brain and are proposed to decorrelate convergent mossy fiber (MF) inputs in service of learning. Interneurons within the GrC layer, Golgi cells (GoCs), are the primary inhibitors of this vast population and therefore play a major role in influencing the computations performed within the layer. Despite this central function for GoCs, few studies have directly examined how GoCs integrate inputs from specific afferents, which vary in density to regulate GrC population activity. We used a variety of methods in mice of either sex to study feedforward inhibition recruited by identified MFs, focusing on features that would influence integration by GrCs. Comprehensive 3D reconstruction and quantification of GoC axonal boutons revealed tightly clustered boutons that focus feedforward inhibition in the neighborhood of GoC somata. Acute whole-cell patch-clamp recordings from GrCs in brain slices showed that, despite high GoC bouton density, fast phasic inhibition was very sparse relative to slow spillover mediated inhibition. Dynamic-clamp simulating inhibition combined with optogenetic MF activation at moderate rates supported a predominant role of slow spillover mediated inhibition in reducing GrC activity. Whole-cell recordings from GoCs revealed a role for the density of active MFs in preferentially driving them. Thus, our data provide empirical confirmation of predicted rules by which MFs activate GoCs to regulate GrC activity levels.

Key words: cerebellum; feedforward inhibition; granule layer; interneurons; mossy fibers; nucleocortical

\section{Significance Statement}

A unifying framework in neural circuit analysis is identifying circuit motifs that subserve common computations. Wide-field inhibitory interneurons globally inhibit neighbors and have been studied extensively in the insect olfactory system and proposed to serve pattern separation functions. Cerebellar Golgi cells (GoCs), a type of mammalian wide-field inhibitory interneuron observed in the granule cell layer, are well suited to perform normalization or pattern separation functions, but the relationship between spatial characteristics of input patterns to GoC-mediated inhibition has received limited attention. This study provides unprecedented quantitative structural details of GoCs and identifies a role for population input activity levels in recruiting inhibition using in vitro electrophysiology and optogenetics.

\section{Introduction}

A fundamental function of the cerebellar granule cell $(\mathrm{GrC})$ is to decorrelate information conveyed via convergent multi-

Received June 7, 2018; revised Nov. 27, 2018; accepted Dec. 13, 2018.

Author contributions: S.T. wrote the first draft of the paper; S.T., J.I.G., and A.L.P. edited the paper; S.T., J.I.G., and A.L.P. designed research; S.T., J.I.G., and A.L.P. performed research; S.T., J.I.G., K.P., and A.L.P. analyzed data; S.T. wrote the paper.

This work was supported by the Japan Society for the Promotion of Science Overseas Research Fellowship and the Uehara Memorial Foundation research fellowship to S.T.; and the Klingenstein Foundation, the Boettcher Foundation Webb-Waring Biomedical Research Award, and National Institutes of Health Grant NS084996 to A.L.P., and Neuroscience Training Grant T32NS 099042 to J.I.G. Imaging experiments were performed in the University of Colorado Anschutz Medical Campus Advance Light Microscopy Core supported in part by Rocky Mountain Neurological Disorders Core Grant P30NS048154 and by National Institutes of Health/National Center for Advancing Translational Sciences Colorado CTSI Grant UL1 TR001082. Engineering support was provided by the Optogenetics and Neural Engineering Core at the University of Colorado Anschutz Medical Campus, supported in part by the National Institute of Neurological Disorders and Stroke of the National Institutes of Health Award P30NS048154. We thank modal mossy fibers (MFs), increasing utility for learned associations (Marr, 1969; Albus, 1971; Billings et al., 2014; CaycoGajic et al., 2017). Recent work has demonstrated that GrCs receive and respond to MFs conveying diverse information (Huang et al., 2013; Ishikawa et al., 2015), but little attention has been paid to the potential role of multimodal integration by Golgi cells (GoCs). GoCs are in a key position to regulate expansion recoding by $\mathrm{GrCs}$ because feedforward inhibition sets spiking threshold and thereby the number of different

Samantha Lewis for expert technical support during the project; and Dr. Christian Rickert for assistance with dynamic-clamp design

The authors declare no competing financial interests.

Correspondence should be addressed to Abigail L. Person at abigail.person@ucdenver.edu.

https://doi.org/10.1523/JNEUROSCl.1448-18.2018

Copyright $\odot 2019$ the authors $\quad 0270-6474 / 19 / 391169-13 \$ 15.00 / 0$ 
afferents required to drive GrC firing (Marr, 1969; D'Angelo et al., 2013). Indeed, theory suggests that feedforward inhibition via GoCs performs a thresholding-like function, clamping the number of active GrCs at a relatively fixed level by engaging GoCs in a scaled manner with increasing activity from MFs (Marr, 1969; Medina et al., 2000).

GoC inhibition of GrCs has been studied extensively in slices and is characteristically diverse. Fast phasic IPSCs, a pronounced slow spillover-mediated component, and "tonic" $\mathrm{GABA}_{\mathrm{A}}$ receptor mediated currents are all forms of inhibition mediated by GoCs (for review, see Farrant and Nusser, 2005; Crowley et al., 2009; D'Angelo and De Zeeuw, 2009; Nieus et al., 2014). The spillover and tonic inhibitory tone within the layer would seemingly provide an ideal mechanism for widely inhibiting the vast number of GrCs without necessarily forming direct contact with each cell. Furthermore, relating $\mathrm{GoC}$ recruitment to the density of active MFs is critical for testing the hypothesis of dynamic thresholding in service of pattern separation.

Another challenge for GoCs is inhibiting the vast number of GrCs to regulate activity within the $\mathrm{GrC}$ layer. GoC axons are famously dense, but details of spatial ramification patterns that define the likelihood of local GrCs sharing inhibition remain undefined. Indeed, the problem of quantitatively addressing the distribution of inhibition from a single GoC was described by Ramon y Cajal: "When one of these axons appears completely impregnated in a Golgi preparation, it is almost impossible to follow its complete arborization .... It is only in the incomplete impregnations of adult animals ... that one can study the course and divisions of the axon. Ramon y Cajal 1890a" (Palay and Chan-Palay, 1974). To our knowledge, this observation remains relevant in contemporary literature where all GoC reconstructions have been incomplete (Simpson et al., 2005; Barmack and Yakhnitsa, 2008; Kanichay and Silver, 2008; Vervaeke et al., 2010, 2012; Szoboszlay et al., 2016; Valera et al., 2016).

To address these questions, we used a variety of methods to resolve $\mathrm{GoC}$ connectivity rules and the capacity of specific afferents to produce fast phasic and slow spillover-mediated inhibition. We performed comprehensive single-cell, high-resolution reconstruction of GoCs with quantitative morphological analysis to estimate glomerular innervation by GoCs. Optogenetic activation of specific MF afferents from the pontine or cerebellar nuclei, which differ systematically in their density, were used with electrophysiological recordings of GoCs from slices to test the prediction that the density of afferent activity engages graded inhibition to regulate $\mathrm{GrC}$ threshold.

\section{Materials and Methods}

\section{Animals}

All procedures followed the National Institutes of Health Guidelines and were approved by the Institutional Animal Care and Use Committee and Institutional Biosafety Committee at the University of Colorado Anschutz Medical Campus. Animals were housed in an environmentally controlled room, kept on a $12 \mathrm{~h}$ light/dark cycle, and had ad libitum access to food and water. Adult mice (2-5 months old) of either sex were used in all experiments; sex was not monitored for experimental groupings. Genotypes used were C57BL/6 (Charles River Laboratories), Neurotensin receptor1-Cre (Ntsr1-Cre; Mutant Mouse Regional Resource Center, STOCK Tg (Ntsr1-cre) GN220Gsat/Mmucd), and GlyT2-eGFP (Salk Institute, $\mathrm{Tg}$ (Slc6a5-EGFP)13Uze) (Zeilhofer et al., 2005). All transgenic animals were bred on a C57BL/6 background and maintained as heterozygotes. Ntsr1-Cre animals were genotyped for Cre, and GlyT2eGFP animals were genotyped for eGFP (Transnetyx).

\section{Virus injections}

For surgical procedures, at least 1-month-old mice were anesthetized with intraperitoneal injections of ketamine hydrochloride $(100 \mathrm{mg} / \mathrm{kg})$ and xylazine $(10 \mathrm{mg} / \mathrm{kg})$ mixture. Mice were placed in a stereotaxic apparatus, and bupivacaine $(6 \mathrm{mg} / \mathrm{kg})$ was injected along the incision line. Craniotomies were made above the cerebellar cortex (from $\lambda:-1.9 \mathrm{~mm}$, $1.1 \mathrm{~mm}$ lateral, $1.2 \mathrm{~mm}$ ventral), interposed nuclei (IN) (from $\lambda:-1.9$ $\mathrm{mm}, 1.1 \mathrm{~mm}$ lateral, $2.4 \mathrm{~mm}$ ventral), and pontine nuclei (from bregma: $-3.7 \mathrm{~mm}, 0.5 \mathrm{~mm}$ lateral, $5.5 \mathrm{~mm}$ ventral). Pressure injections of virus were administered using a pulled glass pipette (7-9 $\mu \mathrm{m}$ tip diameter). Mice were allowed to survive for $>6$ weeks before experiments, which we found in pilot experiments optimized expression of reporter proteins in MF terminals.

\section{Viruses}

AAV8-hSyn1-mCherry-Cre (titer: $10^{2}$, University of North Carolina) and AAV2-CAG-FLEX-eGFP (titer: $10^{12}$, University of Pennsylvania) were coinjected to cerebellar cortex to sparsely label neurons for morphological analysis of GoCs. AAV2-hSyn1-hChR2(H134R)-mCherryWPRE (University of North Carolina Vector Core) were injected to WT mouse IN and pontine nuclei to induce ChR2 expression for electrophysiological recordings. AAV2-EF1a-DIO-hChR2(H134R)-mCherryWPRE-pA was injected into the IN of Ntsr1-Cre mice for a subset of nucleocortical (NC) MF studies (University of North Carolina Vector Core).

\section{Electrophysiology}

Slice preparation. At least 6 weeks after virus injection, mice were deeply anesthetized with isoflurane before transcardial perfusion, and slicing in warm $\left(37^{\circ} \mathrm{C}-40^{\circ} \mathrm{C}\right)$, oxygenated $\left(95 \% \mathrm{O}_{2}-5 \% \mathrm{CO}_{2}\right)$ Tyrode's solution contained the following (in mM): $123.75 \mathrm{NaCl}, 3.5 \mathrm{KCl}, 26 \mathrm{NaHCO}_{3}, 1.25$ $\mathrm{NaH}_{2} \mathrm{PO}_{4}, 1.5 \mathrm{CaCl}_{2}, 1 \mathrm{MgCl}_{2}$, and 10 glucose (Person and Raman, 2011; Ankri et al., 2014). Dissected cerebellum was sliced at $300 \mu \mathrm{m}$ in the coronal plane for $\mathrm{GoC}$ recordings and either parasagittal or coronal planes for GrC recordings on a Leica VT1000S Vibratome. Slices were transferred to an oxygenated Tyrode's solution $\left(37^{\circ} \mathrm{C}\right)$ and incubated for 30-60 min.

In vitro recordings. One hour after slicing for $\mathrm{GrC}$ recordings and immediately after slicing for GoC recordings (Hull and Regehr, 2012), tissue was transferred to the recording chamber. Oxygenated Tyrode's solution $\left(30^{\circ} \mathrm{C}\right)$ was perfused over the slice at $3 \mathrm{ml} / \mathrm{min}$ and visualized with an AxioExaminer (Carl Zeiss) equipped with xenon lamp LAMBDA DG-4 (Sutter Instruments) for optogenetic stimulation through the objective. MFs were stimulated optogenetically with $2 \mathrm{~ms}$ light pulses with a measured power of $18.5 \mathrm{~mW}$ at $473 \mathrm{~nm}\left(0.96-3.77 \mathrm{~mW} / \mathrm{mm}^{2}\right.$, depending on diameter of the light cone at preparation). Pulled glass patch electrodes (GoCs: 2-3.5 $\mathrm{m} \Omega$; GrCs: 4-6 $\mathrm{m} \Omega$; Sutter Instruments, P-97) were filled with K-gluconate-based internal solution containing the following (in mM): $120 \mathrm{~K}$-gluconate, $2 \mathrm{Na-gluconate,} 6 \mathrm{NaCl}, 2 \mathrm{MgCl}_{2}, 1$ EGTA, 4 Mg-ATP, 0.3 Tris-GTP, 14 Tris-creatine phosphate, 10 HEPES, and adjusted for $\mathrm{pH}(7.3)$ with $\mathrm{KOH}$ and osmolarity (290 mOsm) with sucrose. For all $\mathrm{GoC}$ recordings and a subset of $\mathrm{GrC}$ recordings, biocytin ( $0.3 \%$; Tocris Bioscience) was added to the internal solution. Whole-cell recordings were made in current-clamp and voltage-clamp mode, lowpass filtered at $6-10 \mathrm{kHz}$, amplified with a MultiClamp 700C, partially compensated for series resistance, digitized at $10-50 \mathrm{kHz}$ with a Digidata 1550 , and monitored with pClamp acquisition software (Molecular Devices). Blockade of neurotransmitter receptors was achieved with bath application of $10 \mu \mathrm{M}$ RS-CPP (Tocris Bioscience) to block NMDARs and $10 \mu \mathrm{M}$ SR95531 (Tocris Bioscience) to block GABA ${ }_{\mathrm{A}}$ Rs. Data were analyzed with custom routines and with the Neuromatic package (ThinkRandom) in IGOR Pro (Wavemetrics; RRID:SCR_000325). We targeted recordings to locations of ChR2 expression in MFs, particularly Crus 1, 2, Lobule Simplex, and Lobule 4/5.

Dynamic clamp. Dynamic-clamp experiments were performed using a custom-built microcontroller-based dynamic-clamp system with $10 \mu \mathrm{s}$ input-output latency (Desai et al., 2017) (www.dynamicclamp.com). We modified the layout, customized resistors, made a custom 3D printed enclosure, and calibrated the system with details provided as an open resource from the Optogenetics and Neural Engineering Core at the 
University of Colorado Anschutz Medical Campus with modifications publicly available. Simulated current timing was triggered by TTL via a Master-8 Pulse Stimulator (A.M.P.I.). We simulated both MF EPSCs and GoC-mediated IPSCs, with parameters calculated from our GrC recording dataset using optogenetic stimulation of MFs as well as from previous reports (Rossi and Hamann, 1998). Dynamic-clamp inhibitory postsynaptic conductances (IPSGs) mimicked $\mathrm{GABA}_{\mathrm{A}}$ receptor-mediated conductances with a reversal potential of $-70 \mathrm{mV}$ and a linear ohmic current-voltage relation, with kinetics following a single exponential rise and decay model as follows: Fast phasic IPSGs had a $2.15 \mathrm{~ms}$ rise time, $2.29 \mathrm{~ms} \tau_{\text {decay }}$, and a peak conductance of $0.3 \mathrm{nS}$ (small) or $1.2-1.5 \mathrm{nS}$ (large). Slow phasic IPSGs had a $30.2 \mathrm{~ms}$ rise time, $630 \mathrm{~ms} \tau_{\text {decay, }}$ and peak conductances of 0.032 or $0.32 \mathrm{nS}$. These reflected observations made in a subset of recordings in which trains of MF stimuli were made while recording IPSCs in GrCs (see Fig. 5). Both depressing and nondepressing synapses were mimicked. Depressing synapses reflected previous reports from in vivo recordings, where IPSGs rapidly depressed to $\sim 50 \%$ after the first IPSG in a burst (Duguid et al., 2015). Dynamic-clamp mimicking MF-like excitatory postsynaptic conductances (EPSGs) were delivered at $100 \mathrm{~Hz}$ and depressed to a steady state of $50 \%$ across trains (Saviane and Silver, 2006). Each EPSG followed an excitatory synaptic model with peak conductance of $1.5 \mathrm{nS}, 0.4 \mathrm{~ms}$ rise time, and decay time of $1.3 \mathrm{~ms}$ and had a net reversal potential of $0 \mathrm{mV}$, reflecting dual AMPA and NMDA receptor-mediated conductances as described previously (Walcott et al., 2011).

\section{Tissue preparation for light microscopy}

Mice were overdosed with an intraperitoneal injection of a sodium pentobarbital solution, Fatal Plus (Vortech Pharmaceuticals), and perfused transcardially with $0.9 \%$ saline followed by $4 \%$ PFA. Brains were removed and postfixed for at least $24 \mathrm{~h}$ and then cryoprotected in $30 \%$ sucrose. Tissue was sliced in $40 \mu \mathrm{m}$ serial coronal sections using a freezing microtome and stored in $0.1 \mathrm{M} \mathrm{PB}$.

For post hoc morphological analyses following slice electrophysiology, tissue was transferred to warm $4 \%$ paraformaldehyde and postfixed for $<3 \mathrm{~h}$ then placed in $30 \%$ sucrose. Tissue was rinsed in $0.1 \mathrm{M} \mathrm{PB}$ for $30 \mathrm{~min}$ then treated in $0.3 \%$ Triton $\mathrm{X}-100$ in $0.1 \mathrm{M} \mathrm{PB}$ for $2 \mathrm{~h}$ followed by three washes in PB (10 min each). To visualize biocytin, tissue was incubated with streptavidin conjugated to AlexaFluor-647 or -555 (Invitrogen) diluted 1:100 in $0.1 \mathrm{M} \mathrm{PB}$ overnight at $4^{\circ} \mathrm{C}$ followed by three washes in $\mathrm{PB}$ (20 min each).

\section{Imaging}

Confocal images were obtained using Carl Zeiss LSM 780. To reconstruct all processes and/or map all axonal boutons of GoCs, sequential images were taken with diffraction limited resolution achieved via $63 \times$ oil objective with NA 1.4 (Plan-Apochrom $63 \times / 1.4$ oil DIC M27 objective by Ar-Iron laser; $0.39 \mu \mathrm{m} z$ step). This achieved a computed $x, y$ resolution of $175 \mathrm{~nm}$ for the $488 \mathrm{~nm}$ signal and $200 \mathrm{~nm}$ for $561 \mathrm{~nm}$ signal, based on the relationship $\operatorname{Res}_{(x, y)}=\lambda / 2 \mathrm{NA}_{\mathrm{Obj}}$. For MF density analysis, images of filled cells were collected and density analyzed within $53,615 \pm 5180$ $\mu \mathrm{m}^{2}$ of the GoC soma. Images examining MF proximity to GoCs were visualized in Zen software using transparent rendering mode. Highresolution imaging for GlyT2-GFP boutons was performed with a Nikon A1r-HD confocal with a Plan Apo $60 \times$ oil objective, NA 1.4. Deconvolution was performed in NIS-Elements C imaging software.

\section{Morphological analysis}

GoC reconstructions were performed using Neurolucida 360 software (MBF Bioscience; RRID:SCR_001775). Reconstructed GoCs were located in vermal lobule 4/5. Processes were traced in user-guided mode. Fine-grained reconstructions captured axonal and dendritic swellings by adjusting points along processes to match thickness. Because individual GoCs spanned multiple sections, each section was individually reconstructed; then each reconstructed section was stacked using morphological landmarks visible across sections, such as the Purkinje cell layer. To define the relative extent of basal axons and dendrites, we traced these processes with attention to process thickness and contours. Axons were characterized by their smaller diameter $(\sim 0.2 \mu \mathrm{m})$ and were studded with boutons ( $\sim 3 \mu \mathrm{m}$ diameter). For all analyses of reconstructed GoC morphological features, we used Neurolucida Explorer. To define the GrC layer (GCL) volume occupied by the cell, we computed the convex hull volume, which calculates the volume of a convex polygon connecting the tips of the distal processes. To map boutons, we used Neurolucida 360 and placed markers on each bouton with $0.39 \mu \mathrm{m} z$ resolution. All images were aligned, and coordinates of boutons were exported and processed in MATLAB (MathWorks; RRID: SCR_001622). Nearest boutons: All distance analyses used Euclidean distance. Nearest bouton color maps were constructed as 3D scatter plots in MATLAB. Bouton distance probabilities were computed in $0.2 \mu \mathrm{m}$ bins and normalized by the total number of boutons. Comparisons of bouton density between single GoCs and global GlyT2-GFP label were calculated by first computing the local density of boutons for single GoCs, defined as the number of boutons within a $25 \mu \mathrm{m}$ radius sphere of each bouton. The density of GlyT2 boutons was determined by mapping boutons in 6 GlyT2-GFP GCL samples and dividing the total bouton count by the volume of the image. Density measurements were then compared between single GoCs and the GlyT2-GFP ${ }^{+}$population by computing the ratio of bouton densities in a single GoC and mean GlyT2-GFP bouton density. The ratio was used to estimate the fraction of bouton density accounted for by a single GoC. We display the distribution of density ratios in a histogram normalized by the total number of boutons with a bin size of 0.05 .

\section{Experimental design and statistical analysis}

Paired and unpaired $t$ tests were performed using RStudio (version 1.0.136; RStudio). Linear regression analysis was performed using Prism 7.04 software (GraphPad) and MATLAB (RRID:SCR_002798). Statistical tests are specified in the text. Electrophysiological and morphological analyses are described above.

\section{Results}

\section{Spatial distribution of GoC processes}

Rules of integration in GrCs will depend critically on the structure of feedforward inhibition within the GCL. Previous studies have proposed contradictory integrative models. Influential older work proposed that GoC axons tile the GCL in a nonoverlapping manner such that GrCs are innervated by a single GoC (Eccles et al., 1967), yet physiological measurements estimated convergence of multiple GoCs onto GrCs, but the existence of slow spillover current makes convergence estimates challenging (Rossi and Hamann, 1998). Several morphological features of GoCs, including axonal volume and bouton density, are each essential to infer the inhibitory convergence in the GCL. Therefore, we set out to define the density of GoC basal axons to test these assumptions and inform inhibitory connectivity rules in the GCL. We performed comprehensive basal arbor reconstruction to quantify GoC morphological characteristics that contribute to spatial distribution of feedforward inhibition in the GCL. To do so, we used a sparse viral labeling technique, which restricted the number of fluorescent GoCs in cerebellar cortex. A combination of low-titer Cre recombinase-expressing virus (AAV8-hSyn1mCherry-Cre; titer: $10^{2}$ ) and high-titer Cre-dependent reporter virus (AAV2-CAG-FLEX-eGFP; titer: $10^{12}$ ) were injected into cerebellar cortex, which resulted in very sparse labeling of individual GoCs (Fig. 1A).

In keeping with previous reports, sparse GoC label revealed extensive basal axons, which were characterized by their small diameter $(\sim 0.2 \mu \mathrm{m})$ (Palay and Chan-Palay, 1976; Holtzman et al., 2006; Barmack and Yakhnitsa, 2008; Hull and Regehr, 2012; Vervaeke et al., 2012; Ankri et al., 2015; Valera et al., 2016). An example GoC is shown in Figure $1 B$. This GoC extended processes $\sim 200 \mu \mathrm{m}$ mediolaterally, $\sim 330 \mu \mathrm{m}$ dorsoventrally, and $\sim 180 \mu \mathrm{m}$ rostrocaudally, occupying a convex hull volume, or the volume of space occupied by the boundaries of the axonal field, as 

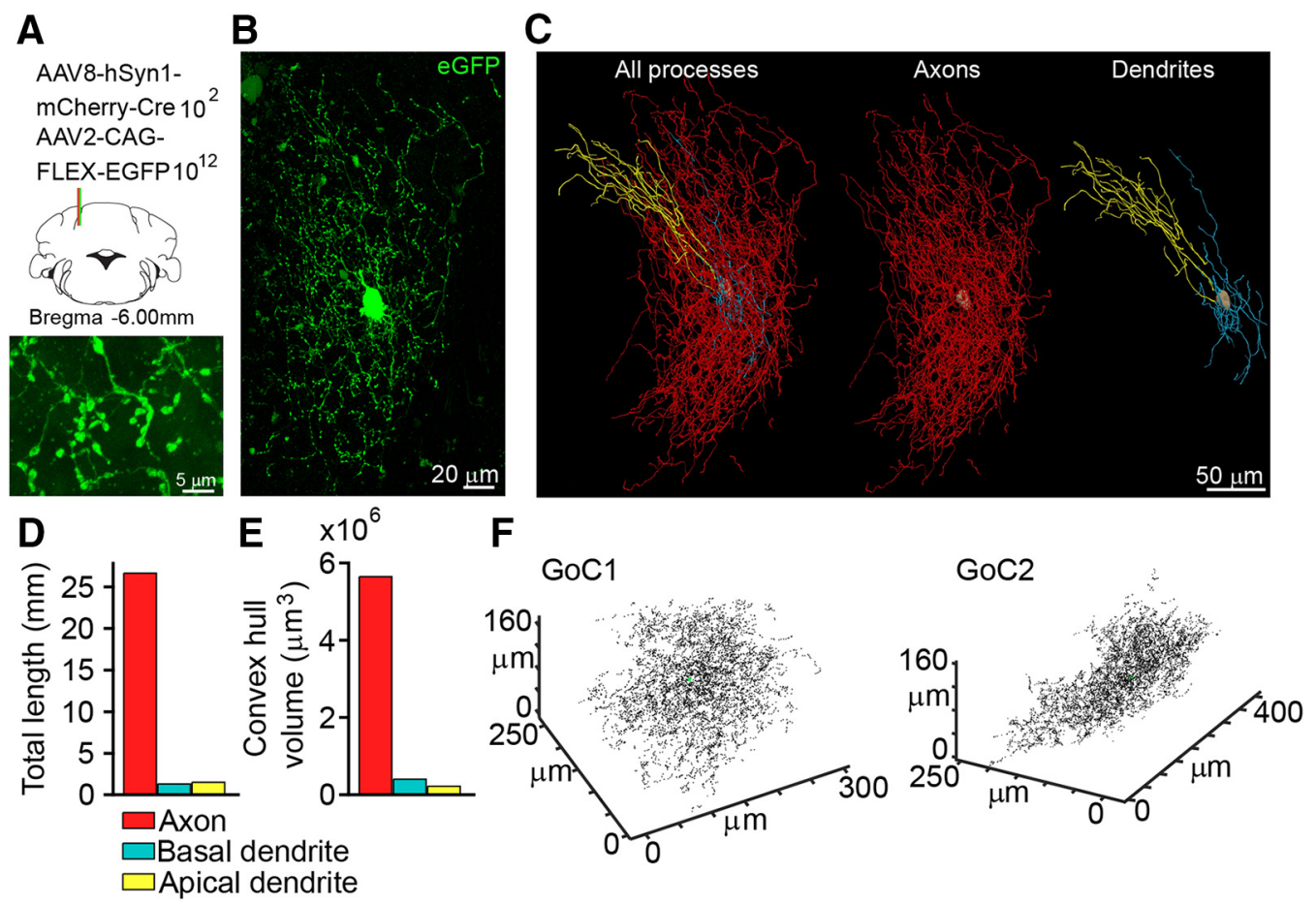

Figure 1. Sparse viral label and comprehensive reconstruction of cerebellar GoCs. A, Schematic of sparse viral labeling technique where low-titer AAV8-hSyn1-mCherry-Cre $10^{2}$ and high-titer AAV2-CAG-FLEX-EGFP $10^{12}$ were coinjected to cerebellar cortex. Bottom, Representative example of GoC axonal boutons. $\boldsymbol{B}$, Example of a sparsely labeled GoC. Scale bar, $20 \mu$ m. $\boldsymbol{C}$, Comprehensive, $3 \mathrm{D}$ reconstruction of $\mathrm{GoC}$ displayed in $2 \mathrm{D}$. Red represents axon. Cyan represents basal dendrite. Yellow represents apical dendrite. Beige represents soma. Left, 0 verview of the single $\mathrm{GoC}$. Middle, Axon processes in GCL. Right, Apical dendrites and basal dendrites. Scale bar, $50 \mu \mathrm{m}$. D, Total length of each process type. $\boldsymbol{E}$, Convex hull volume of each process type. $\boldsymbol{F}$, Maps of axonal boutons from two representative sparsely labeled $\mathrm{G}_{0} \mathrm{Cs}$. Black dots indicate the location of each bouton. Green circle indicates soma.

if a sheet were draped around it, of $\sim 5.7 \times 10^{6} \mu \mathrm{m}^{3}$ and overall axonal length of $26.7 \mathrm{~mm}$ (Neurolucida; see Materials and Methods). Therefore, this GoC basal axon encompasses a volume that contains $\sim 15,000 \mathrm{GrCs}$ and $580 \mathrm{MF}$ rosettes based on estimates of $\mathrm{GrC}$ and MF rosette densities (Palkovits et al., 1971). GoC basal dendrites were distinguishable from axons by their larger diameter $(0.3-3.2 \mu \mathrm{m})$ and smooth surface devoid of boutons as previously described (Palay and ChanPalay, 1974; Hull and Regehr, 2012; Vervaeke et al., 2012; Ankri et al., 2015; Rudolph et al., 2015; Szoboszlay et al., 2016). Dendrites comingled with axons but were considerably shorter (Fig. $1 C$, right), with a length totaling $1.4 \mathrm{~mm}$ (Fig. $1 D$ ) and encompassing a computed volume of $0.41 \times 10^{6} \mu \mathrm{m}^{3}$ (Fig. 1E; convex hull volume; Neurolucida, see Materials and Methods). Because the total axon process was $\sim 20$ times longer than basal dendrites, GoC-mediated inhibition is predicted to be distributed more widely than the afferent input to a given GoC, as has been previously noted (D'Angelo et al., 2013).

The highly restricted cell labeling in vivo also permitted novel quantification of GoC bouton density and numbers. Axons possessed distinct bouton swellings ( $\sim 3 \mu \mathrm{m}$ diameter). We comprehensively mapped boutons of four complete GoCs located in vermal lobule $4 / 5$ and quantified bouton density of an additional partially reconstructed GoC (Fig. $1 F$ ), which was included in a subset of analyses. Axons of individual GoCs were studded with a total of $6000-7500$ boutons $\left(5.9 \times 10^{3}\right.$ to $\left.7.46 \times 10^{3}\right)$, for an average single GoC bouton density of $4.34 \times 10^{5}$ boutons $/ \mathrm{mm}^{3}$ ( $n=4$ from four mice). We calculated the nearest bouton by Euclidean distance, which revealed that a majority (74\%-93\%) were within $4 \mu \mathrm{m}$ of another bouton from the same cell (Fig. $2 A-C$; median nearest bouton, $2.18-3.39 \mu \mathrm{m} ; n=27,402$ bou- tons from 4 cells). The distance from each bouton to its nearest within-cell neighbor remained fairly constant across the axonal arbor (Fig. 2C), illustrated in the color map of nearest neighbors. We quantified this observation with linear regressions relating the nearest bouton distance to its position relative to the soma on a per-cell basis (ranges across cells: $R^{2}=0.0005-0.2$, all $p<0.01$, $F=3.25-54, \mathrm{df}=1893-7811, n=5)$. Although the nearest boutons remained fairly constant across the axonal arbor, visual inspection of the bouton maps suggested clustering toward the soma. We therefore analyzed the number of neighbors within 10 $\mu \mathrm{m}$ of each bouton. This analysis revealed highly structured clustering, where a majority of boutons close to soma had $>20$ close neighbors from the same cell. This clustering dropped as a function of distance from the soma (Fig. $2 D, E ; R^{2}=0.05-0.35$, all $p<0.01, F=213-3100, \mathrm{df}=1893-7811, n=5)$.

These comprehensive bouton maps allowed us to estimate GoC overlap at the glomerulus. To do so, we first compared bouton distributions from single-cell reconstructions with those observed in GlyT2-eGFP mice, which label $~ 85 \%$ of GoCs (Fig. $3 A$ ) (Simat et al., 2007). Mapping boutons in these preparations revealed an overall bouton density of $6.54 \times 10^{6}$ boutons $/ \mathrm{mm}^{3}$. Distributions of nearest boutons differed slightly between single cell reconstructions and GlyT2-eGFP label (Fig. 3B). Not surprisingly, GlyT2-eGFP-labeled boutons were more closely spaced, with a prominent peak at $\sim 1.5 \mu \mathrm{m}$ compared with the peak at 3 $\mu \mathrm{m}$ for the single neurons. Differences between single cells and the population were more pronounced when looking at local clustering, seen by measuring the distances to the closest 10 neighbors (Fig. 3C). GlyT2-eGFP-labeled boutons were denser, with the closest 10 boutons appearing on average $\sim 4 \mu \mathrm{m}$ away from every other bouton from the same cell. By contrast, the nearest 10 boutons to each bouton on axons from individual 

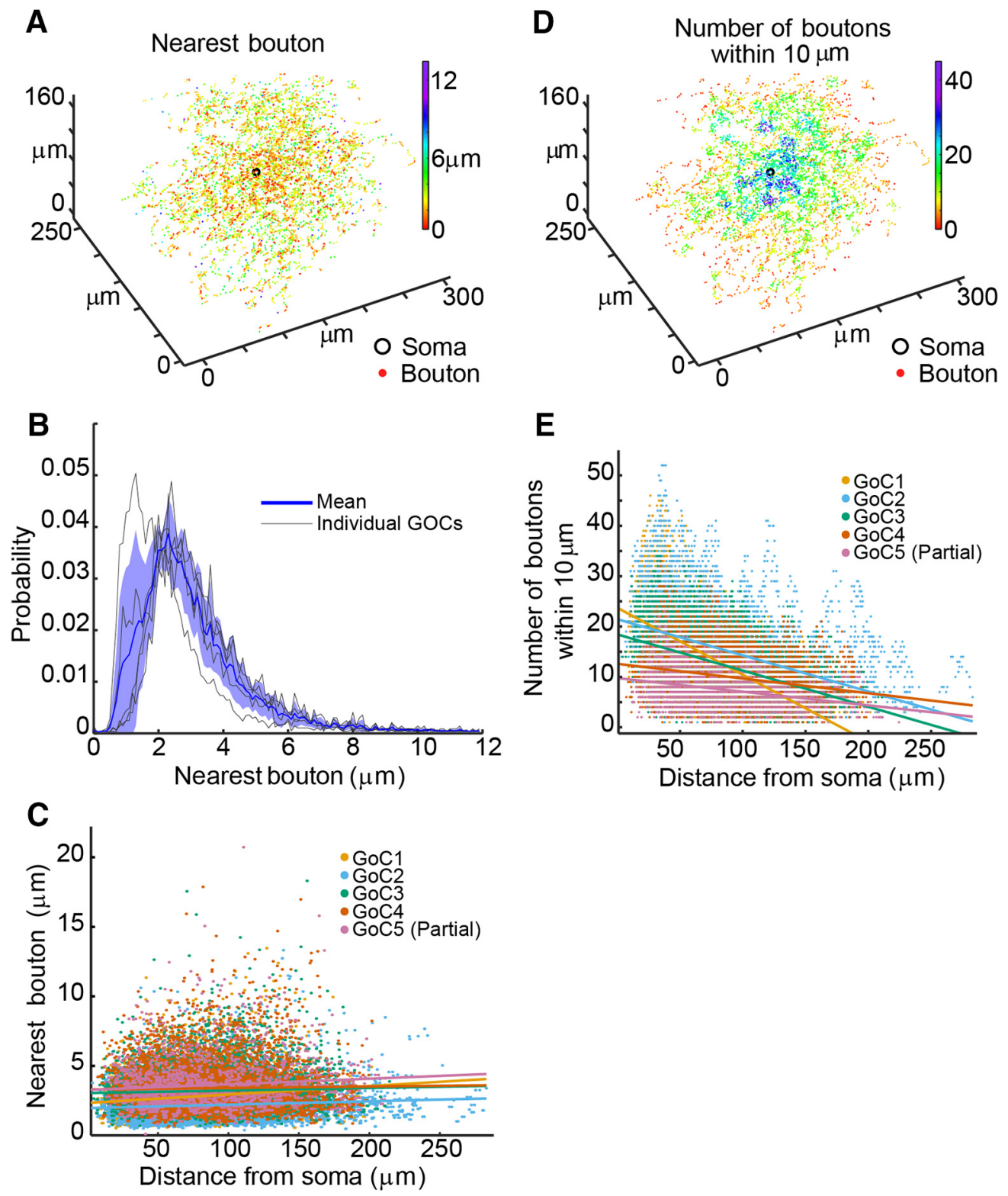

Figure 2. Clustered boutons revealed with high-resolution mapping. $A$, Bouton map of $\mathrm{Go} C$ with distance to the nearest bouton represented by color. $B$, Probability histogram of nearest bouton distances in five GoCs (gray) and mean of five cells (blue, shaded area represents SD). Bin width: $0.1 \mu \mathrm{m}$. C, Summary of nearest boutons as a function of distance from soma. Lines indicate linear regressions plotted for each neuron. $\boldsymbol{D}$, Bouton map of the same GoC shown in $\boldsymbol{A}$ with the number of boutons within $10 \mu \mathrm{m}$ radius from each individual bouton represented by color. $\boldsymbol{E}$, Number of boutons within $10 \mu \mathrm{m}$ radius from each bouton as a function of distance from the soma. Lines indicate linear regressions plotted for each neuron.

neurons averaged $\sim 7 \mu \mathrm{m}$. These analyses allowed us to estimate how many GoC axonal arbors overlap locally. To estimate GoC axonal overlap, we examined the proportion of GlyT2-GFPpositive bouton density accounted for by a single GoC. In areas within $50 \mu \mathrm{m}$ of a GoC soma, single GoC axons tended to account for $40 \%-85 \%$ of bouton density, suggesting that glomeruli here are likely dominated by a single GoC (Fig. 3D). Nevertheless, the proportion of population bouton density accounted for by a single GoC falls off with distance from the GoC soma, as indicated with significant negative slopes of regressions (Fig. $3 D ; R^{2}=0.29-0.66 ; p<0.0001 ; F=768-$ 11600; df $=1895-7811, n=5)$.

The distribution of single GoC:GlyT2 bouton density (Fig. 3E) can be viewed as an estimate of the distribution of the number of overlapping GoCs. The peak in the distributions near 0.2 (mean
$0.22 \pm 0.05$ for complete reconstructions) indicates that a typical degree of overlap between GoCs is $\sim 5$. Assuming that $15 \%$ of GoC boutons remain unlabeled in GlyT2-GFP mice shifts the distribution slightly to peak $\sim 0.18$, suggesting that between 5 and 6 overlapping GoCs is common. Notably, the broad distribution around the peaks indicates a large variance in the number of overlapping GoCs at any position, ranging from 2 to 20 as extremes.

\section{Low-probability fast phasic feedforward inhibition in} the GCL

The spatial extent of GoC processes positions them as sites of MF convergence and inhibitory divergence, motivating experiments examining how feedforward inhibition is recruited by identified cerebellar inputs. To begin to test how diverse MF afferents in- 
A

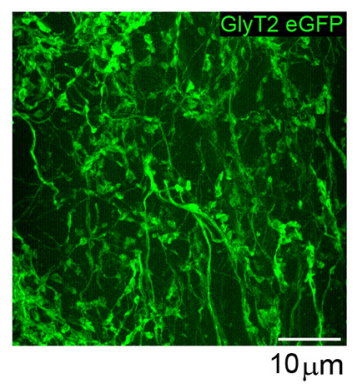

B

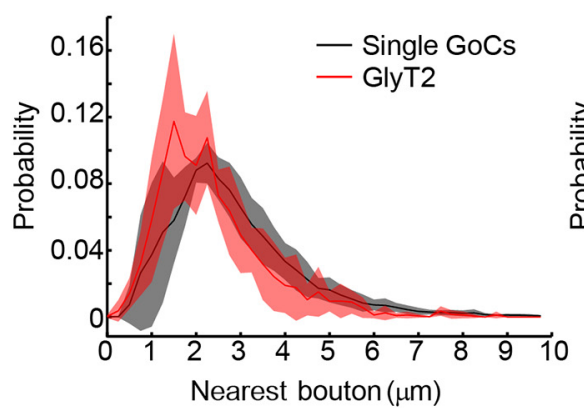

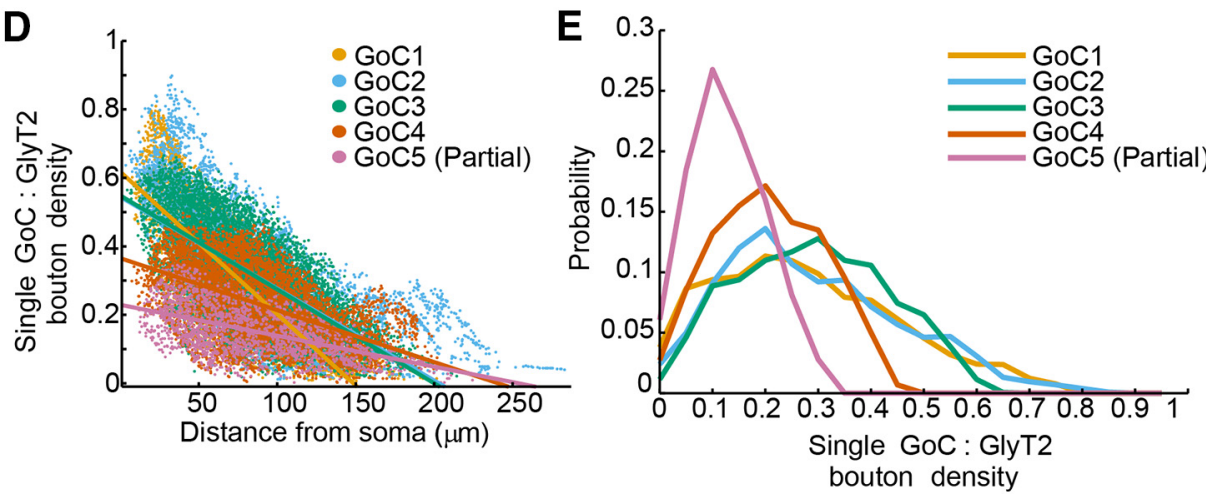

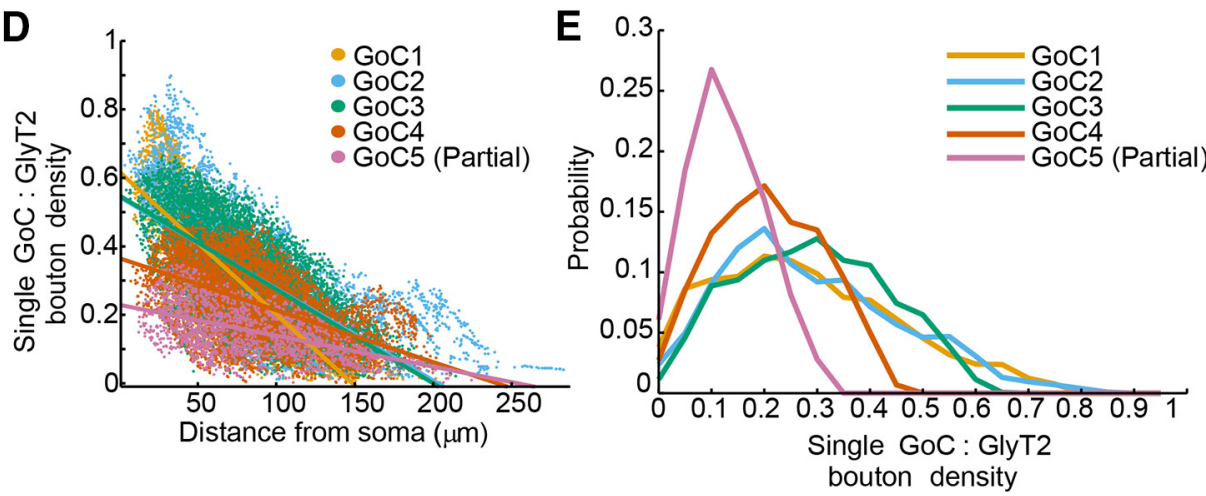

Figure 3. Contribution of single GoCs to population distribution. $\boldsymbol{A}$, GlyT2-eGFP-expressing processes in mouse GCL. Scale bar, $10 \mu \mathrm{m}$. B, Probability histograms of nearest bouton distances for single GoCs (black) and the population of GoCs labeled with GlyT2-GFP (red). Bin width: $0.25 \mu \mathrm{m}$. C, Probability histograms of average distances to the closest 10 boutons from each bouton for single GoCs (black) and a population of GoCs labeled with GlyT2-GFP (red). Bin width: $0.25 \mu \mathrm{m}$. $D$, Ratio of single GoC bouton density to the population-level bouton density as a function of distance from GoC soma. The mean GlyT2 bouton density within a $25 \mu \mathrm{m}$ radius sphere was compared with the number of boutons within a $25 \mu \mathrm{m}$ radius sphere for each bouton in the single GoCs. Lines indicate linear regressions plotted for each neuron. $E$, Probability histogram plotting the ratio of the total GlyT2 bouton density accounted for by one GoC. Bin width: 0.05 .

teract in the GCL, we first scaled down the question to address how identified sources of information recruit GrCs and feedforward inhibition via GoCs. We examined unimodal information processing of GrCs by recording postsynaptic currents evoked by optogenetic stimulation of a subset of MFs originating from neurons in the cerebellar nuclei, known as the nucleocortical (NC) pathway or those originating in the pontine nuclei. AAV2-hSyn 1hChR2-mCherry-WPRE-PA (see Materials and Methods) was injected into either the IN or pontine nuclei to express ChR2 in MFs. In a small subset of experiments, AAV2-EF1a-DIOhChR2(H134R)-mCherry was injected into the IN of Ntsr1-Cre mice, to manipulate the NC pathway. MF density averaged $3673 \pm 1911$ rosettes $/ \mathrm{mm}^{3}$ ( $n=7$ from 5 mice); thus, NC pathway inputs were sparsely spaced, as described previously (Gilmer and Person, 2017). We examined the GrC responses to MF optogenetic stimulation in an acute brain slice preparation from adult mice. We isolated EPSCs and IPSCs by holding GrCs at -70 or 0 $\mathrm{mV}$, respectively, and stimulated ChR2 expressing MFs at between 20 and $60 \mathrm{~Hz}$ with blue light pulses delivered through the objective (Fig. 4A; $2 \mathrm{~ms}$ pulses; $0.96-3.77 \mathrm{~mW} / \mathrm{mm}^{2}$ ).

EPSCs evoked from optogenetic excitation of the NC had an average amplitude of $80.6 \pm 9.3 \mathrm{pA}$ (Fig. $4 B, F$; SEM; $n=7$ ) and $10 \%-90 \%$ rise and $37 \%$ decay times typical of AMPA-type glutamate receptor-mediated currents in GrCs, averaging $0.25 \pm$ $0.04 \mathrm{~ms}$ and $1.0 \pm 0.2 \mathrm{~ms}$, respectively, similar to Group 2 excitatory inputs previously described (Chabrol et al., 2015). Surprisingly, however, given the large spatial convergence of MFs and subsequent divergence of inhibition within the GCL fast phasic IPSCs recorded at $0-3 \mathrm{mV}$ holding potentials were uncommon, observed in just 5 of 12 responsive GrCs and 5 of 96 total GrCs
(Fig. $4 C, G$ : from $N=11$ and $N=18$ mice, respectively). Fast phasic IPSCs were distinct from EPSCs, with smaller amplitudes and slower kinetics, averaging $40.3 \pm 5.5 \mathrm{pA}$, with $0.9 \pm 0.1 \mathrm{~ms}$ $10 \%-90 \%$ rise times and $2.7 \pm 0.4 \mathrm{~ms} 37 \%$ decay times (Fig. $4 \mathrm{I}$; $n=5$; EPSC vs IPSC amplitude, $p=0.007$; rise time, $p<0.001$; decay time, $p=0.001$; unpaired $t$ tests). These measurements were statistically indistinguishable from spontaneous fast phasic inhibitory currents (amplitude, $p=0.1$; rise time, $p=0.3$; decay time, $p=0.2$; unpaired $t$ tests), suggesting that they originate from single GoCs rather than recruitment of multiple convergent GoCs. Moreover, as expected for feedforward inhibition, IPSC latencies and temporal variability were distinct from those of EPSCs (Fig. 4D), averaging $13.5 \pm 0.9 \mathrm{~ms}$ versus $4.2 \pm 0.3 \mathrm{~ms}$ for EPSCs, with latency jitter (SD of latency) averaging $3.6 \pm 0.7 \mathrm{~ms}$ versus $0.29 \pm 0.2 \mathrm{~ms}$ for EPSCs (Fig. $4 E$; $p<0.001$; unpaired $t$ test). Thus, fast phasic inhibition observed in GrCs following NC optogenetic stimulation had the hallmark of feedforward inhibition mediated through GoC recruitment but was nevertheless uncommon.

Given the shared sparseness of direct excitatory and disynaptic phasic inhibitory inputs to GrCs following NC stimulation, we next examined the overlap of these inputs onto single GrCs. As expected for sparse synaptic contacts, GrCs with phasic responses to NC pathway stimulation showed either EPSCs $(58.3 \%)$ or fast phasic IPSCs $(41.6 \%)$ but not both in our recording set (Fig. $4 I$ ). When NC EPSCs were elicited at -70 $\mathrm{mV}$, no fast phasic IPSC was detectable holding the cell at 0 $\mathrm{mV}$; conversely, when IPSCs were evident at $0 \mathrm{mV}$, no EPSC was detectable at $-70 \mathrm{mV}$. 
A

B

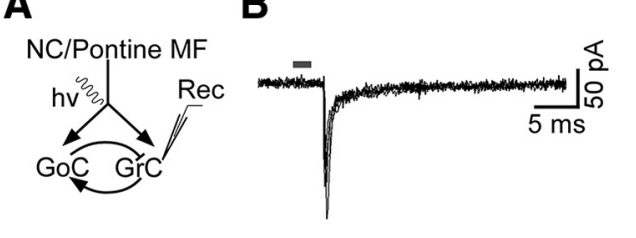

C

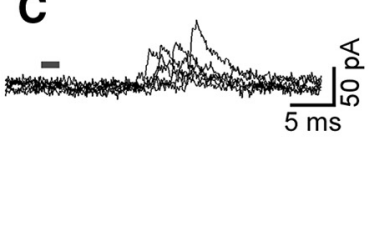

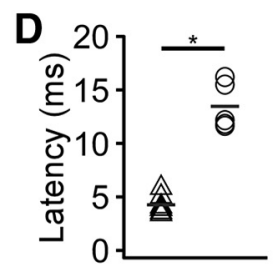

H
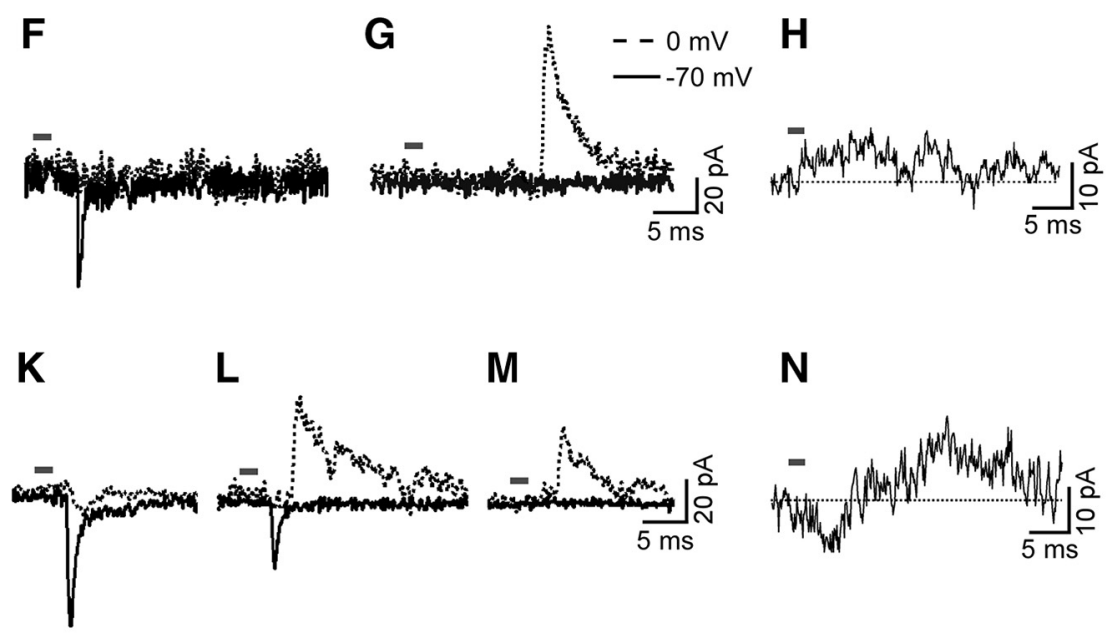

M

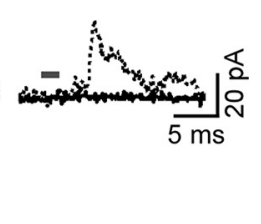

$\mathbf{N}$

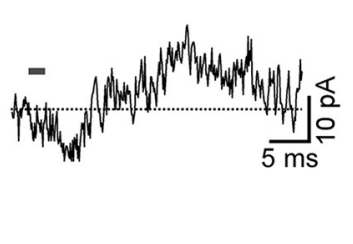

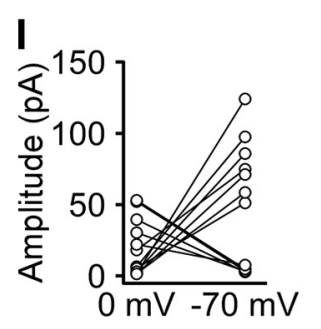
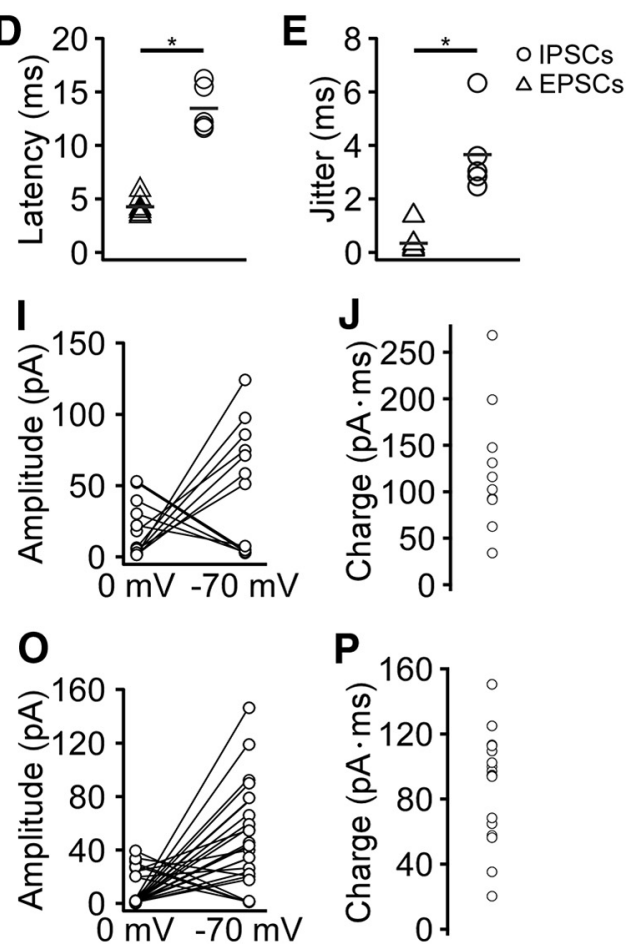

Figure 4. GrC responses to optogenetic activation of identified MF populations. A, Schematic diagram of recording configuration. ChR2-expressing NC or pontine MFs were optogenetically stimulated during GrC recordings. B, C, Overlaid EPSCs or IPSCs evoked by $2 \mathrm{~ms}$ optogenetic stimulation of NC MFs at -70 or $0 \mathrm{mV}$ holding. D, Latency of EPSCs and fast phasic IPSCS ( $p<0.001$; unpaired $t$ test). Gray error bar indicates mean. $\boldsymbol{E}$, Jitter of timing of EPSCs and fast phasic IPSCs was significantly different ( $p<0.001$, unpaired $t$ test). Error bar indicates mean. $\boldsymbol{F}, \mathbf{G}$, Representative traces of responses to light stimulation following NC MF stimulation at $-70 \mathrm{mV}$ (solid lines) and $0 \mathrm{mV}$ (dashed lines). $\boldsymbol{H}$, Example of slow outward current evoked after optogenetic stimulation of $\mathrm{NC}$ pathway at $20 \mathrm{~Hz}, V_{\text {hold }}=0 \mathrm{mV}$.I, Summary of fast phasic current amplitudes recorded at -70 or $0 \mathrm{mV}$.J, Summary of charge transfer during slow outward currents evoked by NCMF stimulation. $\boldsymbol{K}-\boldsymbol{M}$, Same as $\boldsymbol{F}, \boldsymbol{G}$ but for pontine MF stimulation. $\boldsymbol{N}$, Example of slow outward current evoked after optogenetic stimulation of pontine $M F$ s at $20 \mathrm{~Hz}, V_{\text {hold }}=0 \mathrm{mV}$. $\mathbf{0}$, Same as $/$ but for pontine $M F$ stimulation. $\boldsymbol{P}$, Same as $\boldsymbol{J}$ but for pontine MF stimulation. ${ }^{*} p<0.05$.

Slow spillover-mediated inhibition has been proposed as the primary form of inhibition within the GCL, so we next examined GrCs for slow inhibitory currents. Slow inhibitory currents were observed in all GrCs with phasic excitatory or inhibitory responses, with an average charge transfer of $124.5 \pm 21(\mathrm{pA} \cdot \mathrm{ms}$; IPSC area) (Fig. $4 H, J$ ). Thus, slow phasic inhibition dominates feedforward inhibitory processing from identified MF pathways, consistent with observations from electrical stimulation.

To contrast experiments studying low density of MFs from the NC pathway, we next examined GrC responses to a dense MF population originating in the pontine nuclei with optogenetics (Huang et al., 2013; Gilmer and Person, 2017). Labeled pontine MFs were dense, averaging $107,749 \pm 27,965 / \mathrm{mm}^{3}$ (SD) $n=10$ in 5 mice. We made whole-cell patch-clamp recordings of GrCs in the vicinity of labeled MFs. Light stimulation evoked excitatory or fast phasic inhibitory currents in 21 GrCs in 8 mice (Fig. $4 \mathrm{~K}-$ $M)$ : EPSCs, $55.6 \pm 7.6 \mathrm{pA}$, with $0.4 \pm 0.03 \mathrm{~ms} 10 \%-90 \%$ rise times and $1.3 \pm 0.11 \mathrm{~ms} 37 \%$ decay times, $2.8 \pm 0.2 \mathrm{~ms}$ latency $(n=18)$; IPSCs; $22.2 \pm 1.2 \mathrm{pA}$, with $2.2 \pm 0.4 \mathrm{~ms} 10 \%-90 \%$ rise times and $2.3 \pm 0.5 \mathrm{~ms} 37 \%$ decay times; $12.8 \pm 2.1 \mathrm{~ms}$ latency $(n=8)$. The fraction of overlap of phasic EPSCs and fast phasic IPSCs was higher with pontine stimulation, as expected of a denser input: EPSCs without phasic IPSCs were evoked in $62 \%$ of GrCs and exclusively phasic IPSCs were evoked in $14 \%$ of recorded GrCs, constituting $76 \%$ of responsive cells. In the remaining $24 \%$ of responsive neurons, pontine MF stimulation evoked both EPSCs and fast phasic IPSCs (5 of 21) (Fig. 4O). Thus, density of MF afferents influences the overlap between phasic excitation and inhibition. As was observed for NC fibers, how- ever, slow inhibitory currents dominated fast phasic inhibition and were seen in all cells with phasic currents following pontine MF activation, with an average charge transfer of $88 \pm 8.0$ (pA . ms) (Fig. $4 N, P$ ).

To summarize, fast phasic inhibition was probabilistically recruited onto GrCs depending on the approximate density of MF terminals, but slow inhibitory currents were much more widespread, even when evoked by a sparse MF input.

\section{Predominant role of slow spillover inhibition in regulating GrC excitability}

GoC-mediated feedforward inhibition has been proposed to regulate the number of MFs necessary to recruit GrCs. We tested the efficacy of physiological levels of feedforward inhibition regulating $\mathrm{GrC}$ excitability, combining optogenetic stimulation of pontine MFs and dynamic clamp, mimicking physiologically realistic feedforward fast and slow phasic inhibitory conductances ( $N=12$ mice). We recorded from $\mathrm{GrCs}$ in the presence of SR95531 $(10 \mu \mathrm{M})$ to block endogenous $\mathrm{GABA}_{\mathrm{A}}$ receptors. In whole-cell current-clamp mode, we measured $\mathrm{GrC}$ firing in response to $20 \mathrm{~Hz}$ optogenetic stimulation of pontine MFs, followed by delayed fast phasic IPSGs or slow phasic IPSGs produced via the dynamic clamp, mimicking $\mathrm{GoC}$-mediated feedforward inhibition. GrCs were held at -60 to $-75 \mathrm{mV}$ by current injection to promote MF-driven firing. We used two conductances for both fast and slow phasic currents, with the lower of the two matching physiologically measured values but the higher providing insight into the upper bound of physiological levels of inhibition. 

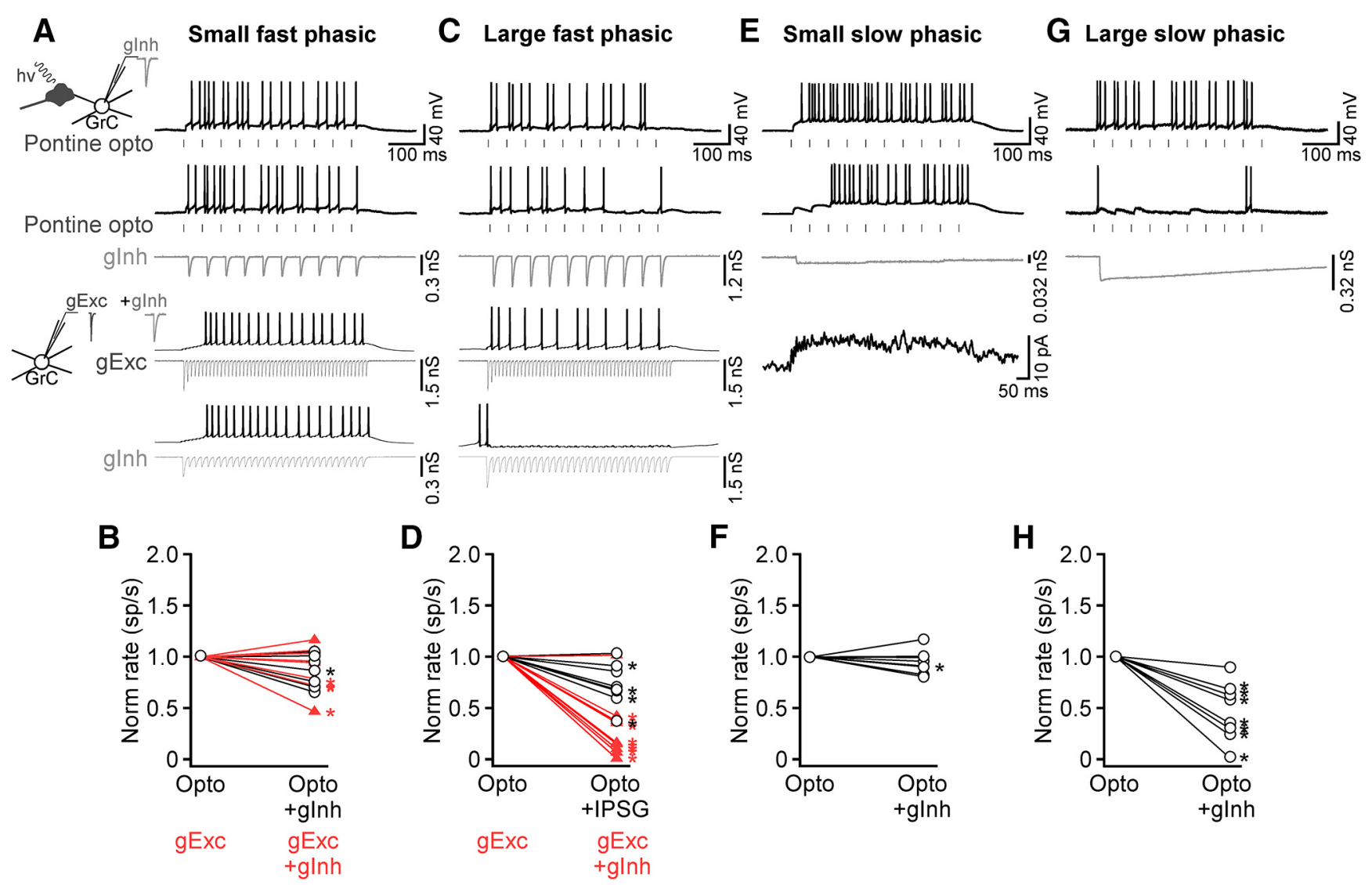

Figure 5. Predominant role for slow feedforward inhibition in regulating GrC synaptic responses at moderate excitation frequency. A, Left, Schematic of recording configuration where dynamic-clamp and optogenetic MF stimulation were combined to examine the role of feedforward inhibition $(\boldsymbol{A})$. Right, Representative traces showing $\mathrm{Gr} C \mathrm{responses}$ to $20 \mathrm{~Hz}$ optogenetic stimulation of pontine MFs without (top) and with (bottom) dynamic-clamp physiological fast phasic IPSGs (bottom). Bottom, The same conventions describe experiments using dynamic clamp to mimic $100 \mathrm{~Hz}$ excitation and $60 \mathrm{~Hz}$ inhibition. $\boldsymbol{B}$, Black represents summary of MF opto-evoked firing rate changes with and without small fast phasic IPSGs. Red represents same but for dynamic-clamp EPSGS + IPSGS. C, D, Same as $\boldsymbol{A}, \boldsymbol{B}$, except with large fast phasic IPSGS. E, $\boldsymbol{F}$, Same as $\boldsymbol{A}, \boldsymbol{B}$, except with small, slow phasic IPSGs. Bottom, Representative trace from GrC in response to $50 \mathrm{~Hz}$ light train illustrating similarity to injected conductance. $\mathbf{G}, \boldsymbol{H}$, Same as $\boldsymbol{A}, \boldsymbol{B}$, except with large, slow phasic IPSGs. Significant changes in firing rate were observed in 7 of $8 \mathrm{GrCs}(p<0.05$, paired $t$ tests). ${ }^{*} p<0.05$.

Low-conductance fast phasic IPSGs $(0.3 \mathrm{nS}$; rise time $2.15 \mathrm{~ms}$, decay tau $2.29 \mathrm{~ms}$ ), approximating a single fast phasic GoC input, were delayed by $12.8 \mathrm{~ms}$ relative to light in a $20 \mathrm{~Hz}$ light pulse 500 $\mathrm{ms}$ train to approximate feedforward inhibition. Across the population, this manipulation did not significantly change optogenetically driven firing compared with optogenetic stimulation alone (Fig. $5 A, B ;-3.9 \pm 2.3 \mathrm{~Hz}$ from baseline, $p>0.1$, paired $t$ test; $n=8$ ), although in one cell fast phasic IPSGs significantly reduced MF-driven firing responses ( 1 of 8 cell; $-10.8 \mathrm{~Hz}$ from baseline, pontine $81.8 \pm 2.0 \mathrm{sp} / \mathrm{s}$, pontine + IPSG $71.0 \pm 1.8 \mathrm{sp} / \mathrm{s}$, unpaired $t$ test, $n=10$ pontine; $n=5$ pontine + IPSG trials; $p=$ 0.002 ). As a positive control, we next tested whether stronger phasic inhibition influenced firing rate. We increased the magnitude of the phasic stimulation to $1.2 \mathrm{nS}$, which is physiologically unlikely because fast phasic contacts are rare and this assumes 4 onto a single cell, when only $60 \%$ of GrC dendrites receive direct contacts (Jakab and Hamori, 1988; Rossi and Hamann, 1998). As expected, this manipulation reduced response frequency (Fig. 5C,D; $-11.9 \pm 3.4 \mathrm{~Hz}$ from baseline, $p<0.05$, paired $t$ test, $n=8$ ), with significant effects seen in 4 of 8 cells ( $p<0.05$, unpaired $t$ test, $n=10$ pontine; $n=5$ pontine + IPSG trials in each cells).

Because MFs are known to burst at much higher rates $(>100$ $\mathrm{Hz}$ ), we also examined the role of phasic inhibitory currents to reduce excitability to higher-frequency stimuli. Optogenetic probes are not well suited to follow such high rates, so we used a dynamic-clamp only approach to mimic both excitation and inhibition. At high rates, GoC inhibitory currents also depress, so we combined high-frequency ( $100 \mathrm{~Hz} ; 1.5 \mathrm{nS}$ peak conductance) EPSGs, which depressed to $\sim 50 \%$ of their maximum amplitude after three stimuli (Saviane and Silver, 2006), and high-frequency IPSGs $(60 \mathrm{~Hz}$ ), which depressed to $50 \%$ after one stimulus (Duguid et al., 2015). Both physiological and large fast phasic inhibitory currents also significantly reduced response rates in some neurons (Fig. $5 B, D ; p<0.05$ for 4 of 11 neurons, mean rate change $-0.9 \pm 1.5$ spikes $/ \mathrm{s} 0.3 \mathrm{nS}$ peak; $p<0.058$ of 9 cells, mean rate change $-19.6 \pm 4.6$ spikes/s, $1.5 \mathrm{nS}$ peak).

In previous dynamic-clamp studies, slow spillover-like inhibitory currents attenuated $\mathrm{GrC}$ firing more effectively than fast phasic IPSCs (Crowley et al., 2009). We extended these experiments to explicitly test a role for feedforward inhibition, such that the slow current was delayed relative to excitation and used conductances mimicking current from a single GoC or higher conductances that reflect summated slow phasic inhibition. We first mimicked slow phasic inhibition observed during $50 \mathrm{~Hz}$ light trains to stimulate MFs (Fig. 5E, bottom), injecting IPSGs (0.032 $\mathrm{nS}$ ) following the first light stimulation, again delayed by $12.8 \mathrm{~ms}$. This experimental condition did not reduce MF driven firing rates (Fig. $5 E ;-4.4 \pm 2.2 \mathrm{~Hz}$ from baseline, $p>0.05$, paired $t$ test, $n=8$ ). Because multiple GoCs converge in a glomerulus, we next 

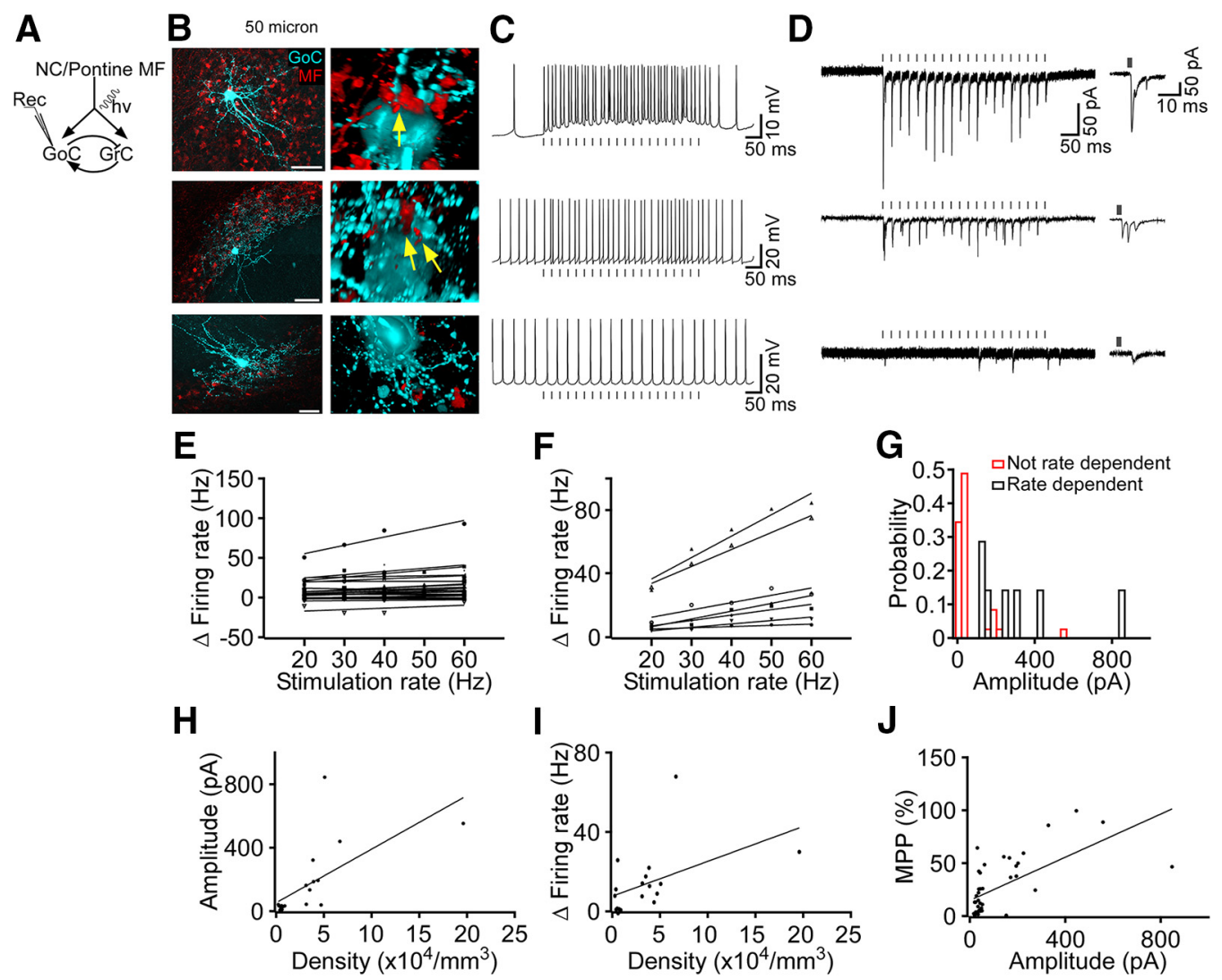

Figure 6. GoC recruitment follows MF population activity levels. A, Schematic diagram of recording configuration. ChR2-expressing NC or pontine MFs were stimulated during GoC recordings. B, Biocytin-filled GoCs (cyan) recovered after recordings show proximity of RFP-expressing MFs. Scale bar, $50 \mu \mathrm{m}$. Right, Putative synaptic contacts (arrows) or absence of contacts between recorded GoC and MF, associated with physiological traces in $\boldsymbol{C}$ and $\boldsymbol{D}$ shown in transparency rendering mode. $\boldsymbol{C}$, Representative examples of $\mathrm{Go} \boldsymbol{C}$ evoked firing in response to optogenetic stimulation of pontine MFs at $40 \mathrm{~Hz}$. Responses varied between cells (top, bottom). $\boldsymbol{D}$, Representative traces showing diversity of evoked EPSCs following optogenetic stimulation of pontine MFs at $40 \mathrm{~Hz}$. $V_{\text {hold }}=-70 \mathrm{mV}$. D, Traces are matched with current-clamp responses in $C$. $E$, $F$, Relationship of $G 0 C$ firing rate change to stimulation rate. $\boldsymbol{E}$, Nonsignificant relationships. $\boldsymbol{F}$, Significant relationships. $\boldsymbol{G}$, Probability distribution of initial EPSC amplitudes measured in GoCs showing significant (black; data from $\boldsymbol{F}$ ) or nonsignificant (red; data from $\boldsymbol{E}$ ) input- output relationships. $\boldsymbol{H}$, Relationship of EPSC amplitude to ChR2-expressing MF density $\left(R^{2}=0.44, p=0.001, F=14.3, \mathrm{df}=18, n=20\right)$. $I$, Relationship of $\mathrm{GoC}$ firing rate change to $40 \mathrm{~Hz}$ stimulation as a function of ChR2-expressing MF density $\left(R^{2}=0.23 ; p=0.04 ; F=5.0 ; \mathrm{df}=16 ; n=18\right) . J$, Multi-EPSC-peak probability plotted as a function of initial EPSC amplitude $\left(R^{2}=0.41, p<0.0001, F=27.9, \mathrm{df}=40, n=42\right)$.

tested higher-conductance IPSGs that reflect summated slow phasic inhibition. We therefore increased conductance 10 -fold capturing summation. As expected, larger slow phasic IPSGs $(0.32 \mathrm{nS}$ ) strongly attenuated rates in most GrCs (Fig. 5G,H; 7 of 8 cells, $p<0.05$, unpaired $t$ test, $n=10$ pontine; $n=5$ pontine + IPSG trials in each cells).

\section{GoC recruitment scales with MF input density}

The dynamic-clamp experiments indicate that fast phasic feedforward inhibition from GoCs regulates the threshold of GrCs (Brickley et al., 1996; Wall and Usowicz, 1997; Rossi and Hamann, 1998; Hamann et al., 2002; Mitchell and Silver, 2003). Threshold regulation was a major role for GoCs in theoretical studies proposing a role for pattern discrimination by $\mathrm{GrCs}$, and predicts that $\mathrm{GoC}$ recruitment would scale with input density (Marr, 1969; Pellionisz and Szentágothai, 1973; Mapelli et al., 2009; Honda and Ito, 2017). Therefore, identifying rules of GoC recruitment is essential to differentiate between diverse models of $\mathrm{GrC}$ information processing.

To better understand the rules of GoC recruitment by identified MF inputs, we next recorded from GoCs directly, measuring evoked firing and synaptic currents following optogenetic stimulation of MFs originating in the cerebellar or pontine nuclei (Fig. 6A). We used GlyT2-eGFP mice to identify GoCs under fluorescence, noting that this excludes a small subpopulation of GoCs from our dataset (Simat et al., 2007). We first tested the efficacy of EPSPs from both NC and pontine sources to drive firing in GoCs in current-clamp mode during trains of stimuli delivered at rates between 20 and $60 \mathrm{~Hz}$ (Fig. 6C). GoCs were spontaneously active during patching, with firing rates spanning $2.4-47.5$ spikes/s. We performed linear regression analysis on firing rate changes as a function of stimulation frequency. Consistent with previous observations from electrical stimulation (Kanichay and Silver, 2008), MF stimulation rates were poor predictors of firing rate changes across the population $\left(R^{2}=0.03\right.$, $p=0.03, F=4.6, \mathrm{df}=176, n=178$ from 36 cells pooled; $N=23$ mice).

This filtering property has been previously ascribed to a large afterhyperpolarization from EPSP-driven spikes (Kanichay and Silver, 2008). Nevertheless, it raises the question of how GrC population activity could remain constant if $\mathrm{GoC}$ recruitment is strongly filtered, prompting us to look closer at the relationship between MF activity and GoCs. Indeed, when we examined the relationship of firing rate with stimulation rate in individual neurons, we noted that some were strongly correlated with significant within-cell correlation (Fig. $6 F ; p<0.04$, $n=7$ ), whereas many cells were not (Fig. $6 E ; p>0.05, n=28$ ). We next examined whether properties of the EPSCs differed 
between these groups and found a strong bias toward stronger EPSCs supporting linear input-output relations (Fig. 6G; $332.1 \pm 41.5 \mathrm{pA}, n=7)$. Weaker EPSCs, by contrast, did not modulate GoC spike rates with increasing stimulus rates (Fig. $6 G ; 71.5 \pm 8.1 \mathrm{pA}, n=35)$.

These findings indicate that EPSC amplitude determines the input-filtering properties of GoCs. To identify factors that influence the amplitude of EPSCs onto GoCs, we took advantage of the fact that optogenetic probes are coupled with a fluorophore; thus, we could directly measure the density of activated inputs. This allowed us test the prediction that MF convergence onto GoCs from multiple inputs would summate to regulate EPSC amplitude in GoCs. Consistent with high levels of convergence of MFs onto GoCs, there was a strong linear relationship between MF density and EPSC amplitude, with higher-density MFs eliciting larger EPSCs (Fig. $6 H ; R^{2}=$ $0.44, p=0.001, F=14.3, \mathrm{df}=18, n=20)$. Despite the sparseness of NC MFs, which constitute just $1 \%-10 \%$ of local MFs (Gilmer and Person, 2017), optogenetic activation of the pathway at $40 \mathrm{~Hz}$ elicited EPSCs in 35\% of GoCs recorded in the vicinity of labeled MFs (34 of 96). Denser MF populations from the pontine nuclei elicited responses in $87 \%$ of nearby GoCs (14 of 16). Not surprisingly, given the large difference in density between pontine and NC inputs pontine inputs elicited significantly larger EPSCs $(p<0.001$, unpaired $t$ test, $-259.5 \pm 26.8 \mathrm{pA}, n=70$ from 14 cells pooled, $-40.7 \pm 3.1$ $\mathrm{pA}, n=131$ from 28 cells pooled, respectively). These observations suggest that GoCs integrate many inputs from diverse sources and are responsive to the level of input population activity as expected for active thresholding.

Having identified a relationship between MF input density and GoC EPSC amplitude and linearity of firing responses, we next reasoned that $\mathrm{GoC}$ firing responses might be sensitive to the overall level of MF activity levels (i.e., the density of active inputs). We tested this idea by analyzing the density of MFs labeled within the vicinity of the recorded GoC, and relating measurements to the magnitude of firing rate changes observed with $40 \mathrm{~Hz}$ stimulation. In keeping with this reasoning, we found a positive significant correlation between active input density and the magnitude of firing rate changes during stimulation (Fig. $6 I ; R^{2}=0.23 ; p=$ $0.04 ; F=5.0 ; \mathrm{df}=16 ; n=18)$.

As described previously (Kanichay and Silver, 2008; Hull and Regehr, 2012; Cesana et al., 2013; Gao et al., 2016), there was considerable diversity in GoC EPSC properties, which differed by amplitude, latency, and whether they were singular or included disynaptic feedback via ascending and parallel fiber input from GrCs. In general, EPSCs fell into three broad classes, which included (1) short latency; (2) mixed short- and long-latency producing multiple peaks per stimulus; and (3) long latency (Fig. 6D). Consistent with the view that these response classes reflect monosynaptic and disynpatic input, biocytin fills of recorded GoCs revealed ChR2-RFP-expressing MF inputs adjacent to somata and/or basal dendrites of shortlatency responders, defined as those with responses occurring within $3.6 \mathrm{~ms}$. Nine of 11 short-latency responders were histologically recovered. In the case of long-latency responders (those with responses $>3.8 \mathrm{~ms}$ ), no MF inputs were identified adjacent to the somata or basal dendrites (Fig. $6 B ; n=3$ of 3 recovered GoCs with long latency responses). Furthermore, bath application of the NMDA receptor antagonist CPP reduced the likelihood of multipeaked EPSC being elicited from $37.9 \pm 14.0 \%$ to $5.8 \pm 1.0 \%(n=3$ cells; $N=3$ mice $)$, sup- porting the view that late synaptic responses were the result of disynaptic recruitment of GrCs (Cesana et al., 2013).

Because GoC multipeaked EPSCs are a readout of $\mathrm{GrC}$ recruitment, which is in turn regulated by GoC inhibitory feedback (Cesana et al., 2013), we reasoned that we could use the relationship between MF input strength and multipeaked EPSC probability to test whether GoCs dynamically modulate MF-GrC gain as predicted in numerous models (Mitchell and Silver, 2003). GoC EPSC multipeak probability was linearly correlated with the initial EPSC amplitude (Fig. 6J; $R^{2}=0.41, p<0.0001, F=27.9$, $\mathrm{df}=40, n=42$ ), indicating that stronger input recruited more GrCs. Interestingly, however, there was no detectable change in multipeak probability or number of peaks over the course of moderate frequency $(40 \mathrm{~Hz})$ stimulus trains $(p=0.68, p=0.65$, paired $t$ test of early vs late train multipeak probability or early vs late train number of peaks per stimulus). This stability of multipeak probability was evident regardless of whether multipeak probability was high or low at the beginning of the stimulus train. Coupled with the observation that $\mathrm{GABA}_{\mathrm{A}}$ receptor blockade strongly enhances multipeak probability (Cesana et al., 2013), these findings indicate that feedback inhibition within the layer stabilizes GrC excitability for a given input excitation level.

\section{Discussion}

This study used a combination of quantitative morphometry, optogenetics, and dynamic clamp to test theoretical predictions about GoCs as global regulators of GrC excitability. Theory has long posited a role for GoCs in regulating $\mathrm{GrC}$ population activity (Eccles et al., 1967; Marr, 1969), proposing that they respond dynamically to varying input levels to modulate all local GrC thresholds, but data testing key assumptions of this view have been lacking. Here we confirm theoretical predictions that GoC axons are ideally suited to globally inhibit neighboring GrCs; that spillover-mediated feedforward inhibition alters $\mathrm{GrC}$ thresholds; and that convergent afferents are essential to recruit GoC inhibition in a manner consistent with a global "listening" mechanism well suited for normalizing activity in the GCL. These data indicate that the large multimodal integrative capacity of the GoC, combined with physiological integrative rules of GrCs, set up an MF activity level-detector to regulate inhibition levels within the GCL.

GrCs have been proposed to perform pattern separation by sparsening information conveyed by MF inputs (Cayco-Gajic et al., 2017). Inhibition from wide-field interneurons has been proposed in both mammalian cerebellum and other systems to perform these computations (Pouille et al., 2009). An underlying but untested assumption is that inhibitory interneurons contact all or nearly all neurons in the field to effectively regulate population activity (Marr, 1969; Albus, 1971; Billings et al., 2014; Duguid et al., 2015; Cayco-Gajic et al., 2017). Similar roles have been proposed for cerebellar GoCs. However, although their morphology has long been appreciated as complex and suitable for widespread inhibition, quantitative analysis of axonal bouton density has not been performed, leading to conflicting speculation about whether inhibition they produce is spatially structured. Our morphometry shows that GoCs are suited to contact every nearby GrC. The ubiquity of boutons throughout the axonal arbor is important in light of potential alterative computations that could distribute inhibition to subsets of neighboring GrCs to decorrelate or temporally sculpt responses. Such findings show that cerebellar GoCs favor a blanket inhibitory process within the region. 
The quantitative morphometry of reconstructed GoCs allowed us to evaluate how a population of GoCs might contribute to spatial distribution of inhibition. Although partial reconstructions of cerebellar GoCs have been published, they have most often followed labeling in brain slices, which necessarily exclude processes leaving or reentering the slice (Kanichay and Silver, 2008; Vervaeke et al., 2010, 2012; Szoboszlay et al., 2016; Valera et al., 2016). Other published reconstructions have followed in vivo labeling but were incomplete (Simpson et al., 2005; Barmack and Yakhnitsa, 2008). Nevertheless, these partial reconstructions support the view advanced here that GoCs are characterized by dense axonal arbors but differ in the extent and orientation of axonal fields (Simpson et al., 2005; Holtzman et al., 2006; Barmack and Yakhnitsa, 2008). Recent work has identified microcircuitry differences between GoCs with distinct molecular identities (Ankri et al., 2015). However, thus far it is unknown whether such connectivity and molecular identities extend to the morphology of GoCs. Future work should relate molecular identity to morphological characteristics to clarify distinct functional roles for GoC subtypes (Simat et al., 2007; Ankri et al., 2015; Eyre and Nusser, 2016).

The comprehensive reconstructions performed here offer insight into a GoC structural motif, where boutons from individual cells remain tightly clustered, even though the overall density of boutons falls off with distance from the soma; that is, their nearest neighbor distances remain constant, whereas the number of close neighbors drops off with distance from the soma. Comparisons of the density of GlyT2-positive GoC boutons, which reflect upward of $85 \%$ of total GoC bouton population, with those of individual cells suggest that within $50 \mu \mathrm{m}$ of a GoC soma, a single GoC dominates the inhibitory axonal population. That dominance shifts as a function of the distance from GoC somata: The distributions of the fraction of the GlyT2 GFP-labeled bouton density accounted for by an individual GoC (Fig. 3E) indicate that a common degree of overlap is $\sim 5 \mathrm{GoC}$ axons because the distributions peak near 0.2 , in line with physiological estimates (Rossi and Hamann, 1998). The broadness of the distributions, however, reveals that the number of overlapping GoCs can vary considerably: between 2 and 20 at extremes. These differences are likely to produce a large variety of inhibitory environments within a population of GrCs and may contribute to diversifying $\mathrm{GrC}$ responses to MF input. Accounting for unlabeled $\mathrm{GoC}$ boutons does not alter these estimates substantially. Based on estimates of glomerular density (Palkovits et al., 1971; Billings et al., 2014), our measurements would suggest that, on average, an individual GoC makes between 0.5 and 1.5 boutons per glomerulus within its axonal field.

The conclusions drawn from the reconstruction data indicate that the GoC is in a position to "globally" inhibit GrCs within range of its axonal arbors, as seen in thresholding motifs (Marr, 1969; Albus, 1971). However, examination of GrCs that were excited by optogenetic activation of MF input revealed surprisingly sparse fast phasic inhibition, even when MF inputs were dense (Fig. 4). This seeming inconsistency was resolved by analyzing GrCs for spillover-like slow inhibitory currents. This form of inhibition, which differs in kinetics and amplitude from direct phasic inhibition, was always observed in GrCs activated by MFs. Slow spillover-mediated IPSCs have been extensively studied in GrCs (Rossi and Hamann, 1998; Mitchell and Silver, 2000; Rossi et al., 2003; Duguid et al., 2012, 2015) and shown to dominate inhibitory processing in GrCs. The difference in likelihood of fast phasic and slow spillover currents, coupled with the extremely high density of GoC boutons, suggested that fast phasic inhibi- tory events occur probabilistically due to the chance spatial proximity of $\mathrm{GrCs}$ dendrites relative to $\mathrm{GoC}$ axonal boutons. This view may be consistent with the observation that "tonic inhibition" is present in the GCL: Tonic inhibition, which lacks resolvable inhibitory current temporal modulation, may be at the end of a continuum of inhibitory current kinetics, where the distance from $\mathrm{GoC}$ glomerular synapses to $\mathrm{GrC}$ dendrite postsynaptic sites dictates kinetics.

Nevertheless, the striking differences between these IPSCs prompted further investigation into the relative physiological roles of these forms of inhibition. Previous dynamic-clamp studies have shown that slow inhibition strongly inhibits GrCs (Crowley et al., 2009; Solinas et al., 2010; Kalmbach et al., 2011; Duguid et al., 2015). We extended these studies by combining physiological levels of inhibition through a dynamic clamp with optogenetic activation of pontine MFs, offset in time from EPSPs. As expected, slow spillover-like conductances, offset in time relative to opto-EPSPs, reduced $\mathrm{GrC}$ responses to both moderatefrequency EPSPs and faster dynamically clamped EPSP trains.

Recent work has shown that MF-mediated feedforward inhibition through GoCs is not solely responsible for modulating $\mathrm{GrC}$ excitability and response timing. For instance, other sources of drive to GoCs have recently been described, including from climbing fibers and serotonin inputs (Nietz et al., 2017; Fleming and Hull, 2018). Moreover, physiological diversity of MF drive to GrCs can modulate GrC response timing (Chabrol et al., 2015), another prominent role ascribed to GoC feedforward inhibition. In addition, the duration and mixture of MFs activated can engage nonlinear recruitment patterns (Hernandez et al., 2018). Thus, future studies should examine ways in which GoCs are recruited either independent of MFs or selectively by particular subpopulations.

Another source of complexity in relating MF activity to recruitment of feedforward inhibition is the fact that EPSP-spike coupling in GoCs is heavily temporally filtered (Kanichay and Silver, 2008; Vervaeke et al., 2010). Our study corroborated reports from several groups finding that GoCs do not reliably follow increasing MF stimulation rates with high fidelity. Because our study involved optogenetic recruitment of MFs labeled with a fluorophore, we could relate GoC activation in our physiology recordings to the density and distribution of MFs activated by light. We uncovered a linear relationship between active MF density and EPSC amplitudes in GoCs elicited by light stimulation, indicative of convergence onto GoCs (Hernandez et al., 2018). Furthermore, MF density related to the firing response elicited at a fixed stimulus rate. In contrast to highly filtered EPSP-GoC firing rate relationships seen across the population and with electrical stimulation, firing rates of GoCs that received the strongest EPSCs from optogenetic stimuli (i.e., those with the highest density of MFs) linearly increased with stimulation rates. These findings relate the density of MF activity to the recruitment of GoCs in a rate-dependent manner, and suggest inhibitory mechanisms within the GCL maintain a large dynamic range by integrating across both MF firing rate and density.

In conclusion, this study relates GoC morphology and unique synaptic physiology onto GrCs to local circuit computations that function to sparsen $\mathrm{GrC}$ activity relative to $\mathrm{MF}$ inputs by reducing excitability. Our data reveal a strikingly dense inhibitory field of local GoCs, analogous to the wide-field inhibitory interneurons in insect mushroom bodies (Papadopoulou et al., 2011) and show that individual GoCs integrate many MF inputs to regulate their output, driving activity that scales with input. Thus, the GoC occupies a key multimodal integrative niche within the layer 
that, compared with the extremely limited extent of the $\mathrm{GrC}$ dendrite, allows for a broader integration of multimodal signals to regulate $\mathrm{GrC}$ population activity.

\section{References}

Albus JS (1971) A theory of cerebellar function. Math Biosci 10:25-61. CrossRef

Ankri L, Yarom Y, Uusisaari MY (2014) Slice it hot: acute adult brain slicing in physiological temperature. J Vis Exp 92:e52068. CrossRef Medline

Ankri L, Husson Z, Pietrajtis K, Proville R, Lena C, Yarom Y, Dieudonne S, Uusisaari MY (2015) A novel inhibitory nucleo-cortical circuit controls cerebellar Golgi cell activity. Elife 4. CrossRef Medline

Barmack NH, Yakhnitsa V (2008) Functions of interneurons in mouse cerebellum. J Neurosci 28:1140-1152. CrossRef Medline

Billings G, Piasini E, Lorincz A, Nusser Z, Silver RA (2014) Network structure within the cerebellar input layer enables lossless sparse encoding. Neuron 83:960-974. CrossRef Medline

Brickley SG, Cull-Candy SG, Farrant M (1996) Development of a tonic form of synaptic inhibition in rat cerebellar granule cells resulting from persistent activation of GABAA receptors. J Physiol 497:753-759. CrossRef Medline

Cayco-Gajic NA, Clopath C, Silver RA (2017) Sparse synaptic connectivity is required for decorrelation and pattern separation in feedforward networks. Nat Commun 8:1116. CrossRef Medline

Cesana E, Pietrajtis K, Bidoret C, Isope P, D’Angelo E, Dieudonné S, Forti L (2013) Granule cell ascending axon excitatory synapses onto Golgi cells implement a potent feedback circuit in the cerebellar granular layer. J Neurosci 33:12430-12446. CrossRef Medline

Chabrol FP, Arenz A, Wiechert MT, Margrie TW, DiGregorio DA (2015) Synaptic diversity enables temporal coding of coincident multisensory inputs in single neurons. Nat Neurosci 18:718-727. CrossRef Medline

Crowley JJ, Fioravante D, Regehr WG (2009) Dynamics of fast and slow inhibition from cerebellar Golgi cells allow flexible control of synaptic integration. Neuron 63:843-853. CrossRef Medline

D’Angelo E, De Zeeuw CI (2009) Timing and plasticity in the cerebellum: focus on the granular layer. Trends Neurosci 32:30-40. CrossRef Medline

D’Angelo E, Solinas S, Mapelli J, Gandolfi D, Mapelli L, Prestori F (2013) The cerebellar Golgi cell and spatiotemporal organization of granular layer activity. Front Neural Circuits 7:93. CrossRef Medline

Desai NS, Gray R, Johnston D (2017) A dynamic clamp on every rig. eNeuro 4:ENEURO.0250-17.2017. CrossRef Medline

Duguid I, Branco T, London M, Chadderton P, Häusser M (2012) Tonic inhibition enhances fidelity of sensory information transmission in the cerebellar cortex. J Neurosci 32:11132-11143. CrossRef Medline

Duguid I, Branco T, Chadderton P, Arlt C, Powell K, Häusser M (2015) Control of cerebellar granule cell output by sensory-evoked Golgi cell inhibition. Proc Natl Acad Sci U S A 112:13099-13104. CrossRef Medline

Eccles JC, Ito M, Szentágothai J (1967) The cerebellum as a neuronal machine. Berlin: Springer.

Eyre MD, Nusser Z (2016) Only a minority of the inhibitory inputs to cerebellar Golgi cells originates from local GABAergic cells. eNeuro 3:ENEURO.0055-16.2016. CrossRef Medline

Farrant M, Nusser Z (2005) Variations on an inhibitory theme: phasic and tonic activation of GABA(A) receptors. Nat Rev Neurosci 6:215-229. CrossRef Medline

Fleming E, Hull C (2018) Serotonin regulates the dynamics of cerebellar granule cell activity by modulating tonic inhibition. J Neurophysiol 121: 105-114. CrossRef Medline

Gao Z, Proietti-Onori M, Lin Z, Ten Brinke MM, Boele HJ, Potters JW, Ruigrok TJ, Hoebeek FE, De Zeeuw CI (2016) Excitatory cerebellar nucleocortical circuit provides internal amplification during associative conditioning. Neuron 89:645-657. CrossRef Medline

Gilmer JI, Person AL (2017) Morphological constraints on cerebellar granule cell combinatorial diversity. J Neurosci 37:12153-12166. CrossRef Medline

Hamann M, Rossi DJ, Attwell D (2002) Tonic and spillover inhibition of granule cells control information flow through cerebellar cortex. Neuron 33:625-633. CrossRef Medline

Hernandez O, Pietrajtis K, Mathieu B, Dieudonné S (2018) Optogenetic stimulation of complex spatio-temporal activity patterns by acoustooptic light steering probes cerebellar granular layer integrative properties. Sci Rep 8:13768. CrossRef Medline
Holtzman T, Rajapaksa T, Mostofi A, Edgley SA (2006) Different responses of rat cerebellar Purkinje cells and Golgi cells evoked by widespread convergent sensory inputs. J Physiol 574:491-507. CrossRef Medline

Honda T, Ito M (2017) Development from Marr's theory of the cerebellum. In: Computational theories and their implementation in the brain: the legacy of David Marr (Vaina LM, Passingham RE, eds), Ed 1. Oxford: Oxford UP.

Huang CC, Sugino K, Shima Y, Guo C, Bai S, Mensh BD, Nelson SB, Hantman AW (2013) Convergence of pontine and proprioceptive streams onto multimodal cerebellar granule cells. Elife 2:e00400. CrossRef Medline

Hull C, Regehr WG (2012) Identification of an inhibitory circuit that regulates cerebellar Golgi cell activity. Neuron 73:149-158. CrossRef Medline

Ishikawa T, Shimuta M, Häusser M (2015) Multimodal sensory integration in single cerebellar granule cells in vivo. Elife 4:e12916. CrossRef Medline

Jakab RL, Hamori J (1988) Quantitative morphology and synaptology of cerebellar glomeruli in the rat. Anat Embryol (Berl) 179:81-88. CrossRef Medline

Kalmbach BE, Voicu H, Ohyama T, Mauk MD (2011) A subtraction mechanism of temporal coding in cerebellar cortex. J Neurosci 31:2025-2034. CrossRef Medline

Kanichay RT, Silver RA (2008) Synaptic and cellular properties of the feedforward inhibitory circuit within the input layer of the cerebellar cortex. J Neurosci 28:8955-8967. CrossRef Medline

Mapelli L, Rossi P, Nieus T, D’Angelo E (2009) Tonic activation of GABAB receptors reduces release probability at inhibitory connections in the cerebellar glomerulus. J Neurophysiol 101:3089-3099. CrossRef Medline

Marr D (1969) A theory of cerebellar cortex. J Physiol 202:437-470. CrossRef Medline

Medina JF, Garcia KS, Nores WL, Taylor NM, Mauk MD (2000) Timing mechanisms in the cerebellum: testing predictions of a large-scale computer simulation. J Neurosci 20:5516-5525. CrossRef Medline

Mitchell SJ, Silver RA (2000) Glutamate spillover suppresses inhibition by activating presynaptic mGluRs. Nature 404:498-502. CrossRef Medline

Mitchell SJ, Silver RA (2003) Shunting inhibition modulates neuronal gain during synaptic excitation. Neuron 38:433-445. CrossRef Medline

Nietz AK, Vaden JH, Coddington LT, Overstreet-Wadiche L, Wadiche JI (2017) Non-synaptic signaling from cerebellar climbing fibers modulates Golgi cell activity. Elife 6:e29215. CrossRef Medline

Nieus TR, Mapelli L, D’Angelo E (2014) Regulation of output spike patterns by phasic inhibition in cerebellar granule cells. Front Cell Neurosci 8:246. CrossRef Medline

Palay S, Chan-Palay V (1974) Cerebellar cortex: Cytology and Organization, pp 100-132. Berlin-Heidelberg: Springer-Verlag.

Palay SL, Chan-Palay V (1976) A guide to the synaptic analysis of the neuropil. Cold Spring Harb Symp Quant Biol 40:1-16. CrossRef Medline

Palkovits M, Magyar P, Szentágothai J (1971) Quantitative histological analysis of the cerebellar cortex in the cat: II. Cell numbers and densities in the granular layer. Brain Res 32:15-30. CrossRef Medline

Papadopoulou M, Cassenaer S, Nowotny T, Laurent G (2011) Normalization for sparse encoding of odors by a wide-field interneuron. Science 332:721-725. CrossRef Medline

Pellionisz A, Szentágothai J (1973) Dynamic single unit simulation of a realistic cerebellar network model. Brain Res 49:83-99. CrossRef Medline

Person AL, Raman IM (2011) Purkinje neuron synchrony elicits timelocked spiking in the cerebellar nuclei. Nature 481:502-505. CrossRef Medline

Pouille F, Marin-Burgin A, Adesnik H, Atallah BV, Scanziani M (2009) Input normalization by global feedforward inhibition expands cortical dynamic range. Nat Neurosci 12:1577-1585. CrossRef Medline

Rossi DJ, Hamann M (1998) Spillover-mediated transmission at inhibitory synapses promoted by high affinity alpha6 subunit $\mathrm{GABA}(\mathrm{A})$ receptors and glomerular geometry. Neuron 20:783-795. CrossRef Medline

Rossi DJ, Hamann M, Attwell D (2003) Multiple modes of GABAergic inhibition of rat cerebellar granule cells. J Physiol 548:97-110. CrossRef Medline

Rudolph S, Hull C, Regehr WG (2015) Active dendrites and differential distribution of calcium channels enable functional compartmentalization of Golgi cells. J Neurosci 35:15492-15504. CrossRef Medline

Saviane C, Silver RA (2006) Fast vesicle reloading and a large pool sustain high bandwidth transmission at a central synapse. Nature 439:983-987. CrossRef Medline 
Simat M, Parpan F, Fritschy JM (2007) Heterogeneity of glycinergic and gabaergic interneurons in the granule cell layer of mouse cerebellum. J Comp Neurol 500:71-83. CrossRef Medline

Simpson JI, Hulscher HC, Sabel-Goedknegt E, Ruigrok TJ (2005) Between in and out: linking morphology and physiology of cerebellar cortical interneurons. Prog Brain Res 148:329-340. CrossRef Medline

Solinas S, Nieus T, D'Angelo E (2010) A realistic large-scale model of the cerebellum granular layer predicts circuit spatio-temporal filtering properties. Front Cell Neurosci 4:12. CrossRef Medline

Szoboszlay M, Lorincz A, Lanore F, Vervaeke K, Silver RA, Nusser Z (2016) Functional properties of dendritic gap junctions in cerebellar Golgi cells. Neuron 90:1043-1056. CrossRef Medline

Valera AM, Binda F, Pawlowski SA, Dupont JL, Casella JF, Rothstein JD, Poulain B, Isope $P$ (2016) Stereotyped spatial patterns of functional synaptic connectivity in the cerebellar cortex. Elife 5:e09862. CrossRef Medline

Vervaeke K, Lorincz A, Gleeson P, Farinella M, Nusser Z, Silver RA (2010)
Rapid desynchronization of an electrically coupled interneuron network with sparse excitatory synaptic input. Neuron 67:435-451. CrossRef Medline

Vervaeke K, Lorincz A, Nusser Z, Silver RA (2012) Gap junctions compensate for sublinear dendritic integration in an inhibitory network. Science 335:1624-1628. CrossRef Medline

Walcott EC, Higgins EA, Desai NS (2011) Synaptic and intrinsic balancing during postnatal development in rat pups exposed to valproic acid in utero. J Neurosci 31:13097-13109. CrossRef Medline

Wall MJ, Usowicz MM (1997) Development of action potential-dependent and independent spontaneous GABAA receptor-mediated currents in granule cells of postnatal rat cerebellum. Eur J Neurosci 9:533-548. CrossRef Medline

Zeilhofer HU, Studler B, Arabadzisz D, Schweizer C, Ahmadi S, Layh B, Bösl MR, Fritschy JM (2005) Glycinergic neurons expressing enhanced green fluorescent protein in bacterial artificial chromosome transgenic mice. J Comp Neurol. 482:123-141. CrossRef Medline 